\title{
Influence of Proton Conducting Cations on the Structure and Properties of 2D Anilate-Based Magnets
}

\author{
Mario Palacios-Corella, ${ }^{\dagger}$ Alejandro Fernández-Espejo, ${ }^{\dagger}$ Montse Bazaga-García, ${ }^{\dagger}$ Enrique R. Losilla, ${ }^{\ddagger}$
} Aurelio Cabeza, ${ }^{\ddagger}$ Miguel Clemente-León, $*{ }^{* \dagger}$ and Eugenio Coronado* ${ }^{\dagger} \dagger$

${ }^{\dagger}$ Instituto de Ciencia Molecular (ICMol), Universidad de Valencia, Catedrático José Beltrán 2, 46980 Paterna, Spain

‡Departamento de Química Inorgánica, Cristalografía y Mineralogía, Facultad de Ciencias, Universidad de Málaga, Campus de Teatinos s/n, 29071 Málaga, Spain

\section{Supporting Information}

ABSTRACT: The syntheses, structures, magnetic, and proton conductivity properties of a family of bimetallic anilate-based compounds with inserted alkylammonium cations are presented. The structures of $\left(\mathrm{Me}_{2} \mathrm{NH}_{2}\right)\left[\mathrm{Mn}^{\mathrm{II}} \mathrm{Cr}^{\mathrm{III}}\left(\mathrm{Br}_{2} \mathrm{An}\right)_{3}\right] \cdot 2 \mathrm{H}_{2} \mathrm{O}$ (1), $\left(\mathrm{Et}_{2} \mathrm{NH}_{2}\right)$ $\left[\mathrm{Mn}^{\mathrm{II}} \mathrm{Cr}^{\mathrm{III}}\left(\mathrm{Br}_{2} \mathrm{An}\right)_{3}\right](2),\left(\mathrm{Et}_{3} \mathrm{NH}\right)\left[\mathrm{Mn}^{\mathrm{II}} \mathrm{Cr}^{\mathrm{III}}\left(\mathrm{Cl}_{2} \mathrm{An}\right)_{3}\right](3)$, and $\left[(\mathrm{Et})(\mathrm{i}-\mathrm{Pr})_{2} \mathrm{NH}\right]$ $\left[\mathrm{Mn}^{\mathrm{II}} \mathrm{Cr}^{\mathrm{III}}\left(\mathrm{Br}_{2} \mathrm{An}\right)_{3}\right] \cdot\left(\mathrm{CHCl}_{3}\right)_{0.5} \cdot\left(\mathrm{H}_{2} \mathrm{O}\right)$ (4) contain a $2 \mathrm{D}$ anionic network formed by $\mathrm{Mn}(\mathrm{II})$ and $\mathrm{Cr}$ (III) ions linked through anilate ligands. In 1, 2, and 3, the hexagonal holes of this network are occupied by $\mathrm{Me}_{2} \mathrm{NH}_{2}{ }^{+}, \mathrm{Et}_{2} \mathrm{NH}_{2}{ }^{+}$, or $\mathrm{Et}_{3} \mathrm{NH}^{+}$cations. Interestingly, the small increase of size of the templating cation in $4\left(\left[(\mathrm{Et})(\mathrm{i}-\mathrm{Pr})_{2} \mathrm{NH}\right]^{+}\right.$in the place of $\mathrm{Me}_{2} \mathrm{NH}_{2}^{+}, \mathrm{Et}_{2} \mathrm{NH}_{2}^{+}$or $\left.\mathrm{Et}_{3} \mathrm{NH}^{+}\right)$, gives rise to a different structure with half of the cations placed within the layers and the other one in the space between the layers. This leads to bilayers with an interlayer separation similar to those of $\mathbf{1}, \mathbf{2}$, and 3 separated by larger interbilayer distances. Compounds 1, 2, and 3 show a ferrimagnetic ordering with a $T_{\mathrm{c}}$ of $8.0 \mathrm{~K}(1), 8.9 \mathrm{~K}(2)$, and $8.0 \mathrm{~K}(3)$. In 4, the presence of different

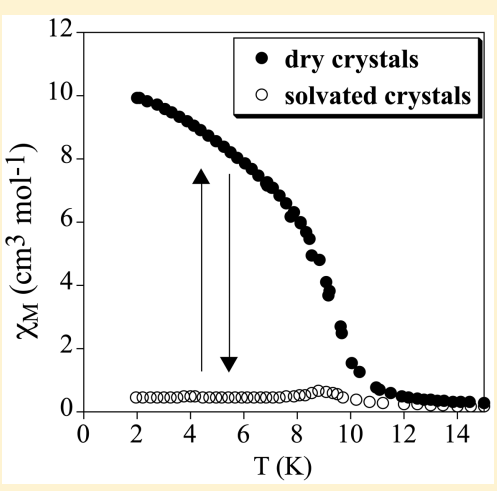
interlayer distances leads to a metamagnetic behavior when the sample is measured in contact with the mother liquor. The behavior changes in the dry sample, which shows a ferrimagnetic ordering as that of $\mathbf{1}, \mathbf{2}$, and 3 due to collapse of the structure as confirmed by powder X-ray diffraction. Interestingly, the metamagnetic behavior is recovered after reimmersing the crystals in the mother liquor proving the reversibility of the process. All solids are Grotthuss-type proton conductors with conductivity values ranging between $2.3 \times 10^{-6} \mathrm{~S} \cdot \mathrm{cm}^{-1}$ for 3 and $2.4 \times 10^{-5} \mathrm{~S} \cdot \mathrm{cm}^{-1}$ for 1 measured at $70{ }^{\circ} \mathrm{C}$ and $95 \%$ relative humidity and activation energies of $\sim 0.2 \mathrm{eV}$.

\section{INTRODUCTION}

The formation of extended solids that combine magnetic ordering with a second property is one of the most appealing topics in chemical science. A rational approach to design this type of multifunctional compounds is the use of extended anionic magnetic lattices, in which the choice of the appropriate countercation provides the second property of interest. ${ }^{1}$

This strategy has been exhaustively investigated in oxalatebased networks. ${ }^{2}$ Thus, compounds combining the cooperative magnetism from the oxalate network with paramagnetism, ${ }^{3}$ photochromism, ${ }^{4}$ electrical conductivity, ${ }^{5}$ ferroelectricity, ${ }^{6}$ chirality, ${ }^{7}$ single-molecule magnetic behavior, ${ }^{8}$ or spin-crossover properties $^{9}$ have been reported. Several groups have explored the use of hydrophilic cations to grow bimetallic $2 \mathrm{D}$ or $3 \mathrm{D}$ oxalate-based networks as proton mediators or proton carriers. This has allowed the preparation of oxalate-based magnets at very low-temperatures $(<12 \mathrm{~K})$ with high proton conductivities at room temperature such as $0.8 \times 10^{-4} \mathrm{~S} \cdot \mathrm{cm}^{-1}$ at $65 \% \mathrm{RH}$ in $\left\{\mathrm{NMe}_{3}\left(\mathrm{CH}_{2} \mathrm{COOH}\right)\right\}\left[\mathrm{FeCr}(\mathrm{ox})_{3}\right] \cdot 3 \mathrm{H}_{2} \mathrm{O}$ or $1.1 \times 10^{-3} \mathrm{~S} \cdot \mathrm{cm}^{-1}$ at $95 \% \mathrm{RH}$ in $\left(\mathrm{NH}_{4}\right)_{2}\left[\mathrm{MnCr}_{2}(\mathrm{ox})_{6}\right] \cdot 34 \mathrm{H}_{2} \mathrm{O} .{ }^{10}$

An alternative source for this type of coordination polymers is based on 2,5-dihydroxy-1,4-benzoquinone dianion and derivatives of formula $\mathrm{C}_{6} \mathrm{O}_{4} \mathrm{X}^{2-}{ }_{2}$ (anilates, $\mathrm{X}_{2} \mathrm{An}^{2-} ; \mathrm{X}=\mathrm{F}, \mathrm{Cl}$,
Br or I, see Scheme 1). Both 2D and 3D homometallic anilatebased compounds have been reported in the literature. ${ }^{11}$ These

Scheme 1. 2,5-Dihydroxy-1,4-benzoquinone Dianion Derivatives<smiles>[X]C1=C([O-])C(=O)C([X])=C([O-])C1=O</smiles>

$\mathrm{X}=\mathrm{F}, \mathrm{Cl}, \mathrm{Br}, \mathrm{I}\left(\mathrm{X}_{2} \mathrm{An}^{2}\right)$, or $\mathrm{X}=\mathrm{H}\left(\mathrm{dhbq}^{2}\right)$.

ligands present similar coordination and bridging modes as the oxalate ones with several advantages: (i) they are easier to modify or functionalize than the oxalates by changing the $\mathrm{X}$ group; (ii) they present higher magnetic ordering temperatures; (iii) their bigger size may give rise to porous compounds. The

Received: August 3, 2017

Published: November 1, 2017 
first heterometallic lattices based on the anilate ligand were the compounds of formula $\mathrm{A}\left[\mathrm{M}^{\mathrm{II}} \mathrm{M}^{\mathrm{III}}\left(\mathrm{X}_{2} \mathrm{An}\right)_{3}\right] \cdot \mathrm{G}\left(\mathrm{A}=\left[\left(\mathrm{H}_{3} \mathrm{O}\right)\right.\right.$ $\left.(\mathrm{phz})_{3}\right]^{+}(\mathrm{phz}=$ phenazine $)$ or $\mathrm{NBu}_{4}{ }^{+} ; \mathrm{M}^{\mathrm{II}}=\mathrm{Mn}, \mathrm{Fe}, \mathrm{Co} ; \mathrm{M}^{\mathrm{III}}=$ $\mathrm{Cr}, \mathrm{Fe} ; \mathrm{X}=\mathrm{H}, \mathrm{Cl}, \mathrm{Br}, \mathrm{I} ; \mathrm{G}=$ water or acetone). ${ }^{12}$ These compounds show a $2 \mathrm{D}$ honeycomb structure. More recently, spin-crossover cations such as $\left[\mathrm{Fe}^{\mathrm{III}}\left(\mathrm{sal}_{2} \text {-trien }\right)\right]^{+}$and $\left[\mathrm{Fe}^{\mathrm{III}}\left(\mathrm{acac}_{2} \text {-trien }\right)\right]^{+}$were used to prepare bimetallic $2 \mathrm{D}$ anilate-based compounds. ${ }^{13,14}$ The reduction of size of $\left[\mathrm{Fe}^{\mathrm{III}}\left(\mathrm{acac}_{2} \text {-trien }\right)\right]^{+}$with respect to $\left[\mathrm{Fe}^{\mathrm{III}}\left(\mathrm{sal}_{2} \text {-trien }\right)\right]^{+}$afforded a new type of structure in which the charge-compensating cations were placed inside the hexagonal channels of the 2D network, instead of being inserted in the interlamellar spacing as in the previous oxalate and anilate $2 \mathrm{D}$ networks. ${ }^{14}$ As for graphene, these layered materials could be mechanically exfoliated in atomically thin layers with heights down to 2 $\mathrm{nm}$ by using the well-known Scotch tape method. In the last two years, the groups of Harris and Long have proven that the partial reduction of 2,5-dihydroxy-1,4-benzoquinone ligands and derivatives can lead to homometallic compounds showing coexistence of high magnetic ordering temperatures and electronic conductivity. Thus, a 3D compound with coexistence of a magnetic ordering with a $T_{\mathrm{c}}=26 \mathrm{~K}$ and high electronic conductivity $\left(0.16 \pm 0.01 \mathrm{~S} \cdot \mathrm{cm}^{-1}\right.$ at $\left.298 \mathrm{~K}\right)$ was prepared by Long et al. ${ }^{15}$ On the other hand, Harris et al. prepared a $2 \mathrm{D}$ porous compound with high conductivity $\left(1.4(7) \times 10^{-2} \mathrm{~S}\right.$. $\mathrm{cm}^{-1}$ at $\left.300 \mathrm{~K}\right)$ and a solvent-induced switching of the magnetic ordering from $T_{c}=26$ to $80 \mathrm{~K}$ of formula $\left(\mathrm{Me}_{2} \mathrm{NH}_{2}\right)_{2}\left[\mathrm{Fe}_{2}\left(\mathrm{~L}_{1}\right)_{3}\right] \cdot 2 \mathrm{H}_{2} \mathrm{O} \cdot 6 \mathrm{DMF}$ where $\mathrm{L}_{1}$ is a mixture of $\mathrm{Cl}_{2} \mathrm{An}^{2-}$ and its reduced semiquinone ligand $\left(\left(\mathrm{L}_{1}\right)_{3}{ }^{2-}\right)$ and DMF is dimethylformamide. ${ }^{16}$ More recently, the same group has demonstrated that this compound undergoes a singlecrystal-to-single-crystal one-electron reduction to give $\left(\mathrm{CoCp}_{2}\right)_{1.43}\left(\mathrm{Me}_{2} \mathrm{NH}_{2}\right)_{1.57}\left[\mathrm{Fe}_{2} \mathrm{~L}_{3}\right] \cdot 4.9 \mathrm{DMF}$ after soaking in a DMF solution of cobaltocene. This compound shows very high magnetic ordering temperature $\left(T_{\mathrm{c}}=105 \mathrm{~K}\right)$ and electrical conductivity. ${ }^{17}$ Very recently, S. Benmansour et al. have shown that reduction of the ligand is not necessary to give high electrical conductivities as the $2 \mathrm{D}$ compounds, $\left[\left(\mathrm{H}_{3} \mathrm{O}\right)\left(\mathrm{H}_{2} \mathrm{O}\right)\right.$ $\left.(\mathrm{phz})_{3}\right]\left[\mathrm{Fe}^{\mathrm{II}} \mathrm{Fe}^{\mathrm{III}}\left(\mathrm{X}_{2} \mathrm{An}\right)_{3}\right] \cdot 12 \mathrm{H}_{2} \mathrm{O}(\mathrm{X}=\mathrm{Cl}$ and $\mathrm{Br})$, present 0.06 and $0.004 \mathrm{~S} \cdot \mathrm{cm}^{-1}$ conductivity values at room temperature attributed to the $\mathrm{Fe}$ (II) $/ \mathrm{Fe}$ (III) mixed valence. ${ }^{18}$

In this work, we have explored the use of alkylammonium cations of increasing size, $\mathrm{Me}_{2} \mathrm{NH}_{2}^{+}, \mathrm{Et}_{2} \mathrm{NH}_{2}{ }^{+}, \mathrm{Et}_{3} \mathrm{NH}^{+}$, and $\left[(\mathrm{Et})(\mathrm{i}-\mathrm{Pr})_{2} \mathrm{NH}\right]^{+}$, as templating cations for the growth of bimetallic anilate networks. The relatively small size of these cations could afford the formation of new networks in which the cations are placed into the hexagonal channels of the anilate-based network as reported before for $\left[\mathrm{Fe}^{\mathrm{III}}\left(\mathrm{acac}_{2}-\right.\right.$ trien) $]^{+}$cations. This could help to understand if there is a critical cation size for the formation of this type of structure and lead to new properties related to the different organizations of the anilate-based layers. On the other hand, the use of these cations could provide proton conduction to the systems thanks to the presence of acidic $\mathrm{NH}$ groups. As mentioned above, the formation of oxalate-based proton conducting materials has been explored previously leading to very interesting results but, to our knowledge, there are no reports of bimetallic anilatebased networks using the same type of cations. Possible advantages of the anilate-based networks to reach this goal are the larger size of the hexagonal channels, which could provide additional paths for proton conduction between cations placed in different layers, and the higher $T_{c} s$ of the magnetic ordering, especially when anilate ligands are reduced. This could help to reduce the large gap between the temperatures at which proton conductivity and magnetic ordering occur in the oxalate-based compounds.

\section{EXPERIMENTAL SECTION}

General Information. Reagents and Materials. The starting reagents were from commercial sources and used as received.

Thermogravimetric analysis (TGA) data were recorded on a SDTQ600 analyzer TA Instruments. Measurements were carried out on samples in open platinum crucibles under air flow from room temperature up to $600{ }^{\circ} \mathrm{C}$ at a heating rate of $10^{\circ} \mathrm{C} \cdot \mathrm{min}^{-1}$. Elemental analyses $(\mathrm{C}, \mathrm{H}$, and $\mathrm{N})$ were performed with a Pekin-Elmer 240 analyzer.

Syntheses. The synthesis of the anilate precursor, $\left(\mathrm{Et}_{3} \mathrm{NH}\right)_{3}[\mathrm{Cr}-$ $\left.\left(\mathrm{Cl}_{2} \mathrm{An}\right)_{3}\right] \cdot \mathrm{H}_{2} \mathrm{O}$, was performed as reported in the literature. ${ }^{19}$

Synthesis of $\left(\mathrm{Me}_{2} \mathrm{NH}_{2}\right)_{3}\left[\mathrm{Cr}\left(\mathrm{Br}_{2} \mathrm{An}\right)_{3}\right] \cdot 2 \mathrm{H}_{2} \mathrm{O}$. Bromanilic acid (500 $\mathrm{mg}, 1.68 \mathrm{mmol}$ ) was dissolved in $50 \mathrm{~mL}$ of acetonitrile, and $0.65 \mathrm{~mL}$ $(3.87 \mathrm{mmol})$ of a solution of dimethylamine ( $40 \%$ in water) was added. A white-pink precipitate appeared. A solution of $330 \mathrm{mg}(0.66$ $\mathrm{mmol})$ of $\mathrm{KCr}\left(\mathrm{SO}_{4}\right)_{2} \cdot 12 \mathrm{H}_{2} \mathrm{O}$ in $15 \mathrm{~mL}$ of water was added, and the mixture turned into a purple solution. The solution was refluxed overnight and filtered. After 5 days, a dark purple crystalline powder was obtained and collected by filtration. FT-IR $\left(\nu / \mathrm{cm}^{-1}, \mathrm{KBr}\right.$ pellets): 3439(m), 3062(w), 3019(w), 2952(w), 2781(w), 1623(m), 1519(vs), 1346(vs), 1306(s), 1018(w), 989(m), 811(m), 602(m), 558(m), 505(w), 409(w).

Anal. Calcd (\%) for $\left(\mathrm{Me}_{2} \mathrm{NH}_{2}\right)_{3}\left[\mathrm{Cr}\left(\mathrm{Br}_{2} \mathrm{An}\right)_{3}\right] \cdot 2 \mathrm{H}_{2} \mathrm{O}$ : C, 25.88; H, 2.53; N, 3.77\%. Found: C, 24.43; H, 2.36; N, 3.41\%.

Synthesis of $\left(\mathrm{Et}_{2} \mathrm{NH}_{2}\right)_{3}\left[\mathrm{Cr}\left(\mathrm{Br}_{2} \mathrm{An}\right)_{3}\right]$. Bromanilic acid $(500 \mathrm{mg}$ $1.68 \mathrm{mmol}$ ) was dissolved in $50 \mathrm{~mL}$ of acetonitrile, and $0.435 \mathrm{~mL}$ $(4.15 \mathrm{mmol})$ of a solution of diethylamine $(99.5 \%$ in water) was added. A white-pink precipitate appeared. A solution of $280 \mathrm{mg}(0.56$ $\mathrm{mmol})$ of $\mathrm{KCr}\left(\mathrm{SO}_{4}\right)_{2} \cdot 12 \mathrm{H}_{2} \mathrm{O}$ in $15 \mathrm{~mL}$ of water was added, and the mixture turned into a purple solution. The solution is refluxed overnight and filtered. After 5 days, a dark purple crystalline powder was obtained and collected by filtration. FT-IR $\left(\nu / \mathrm{cm}^{-1}, \mathrm{KBr}\right.$ pellets): 3442(m), 3043(w), 2986(w), 2926(w), 2841(w), 2777(w), 1636(m), 1518(vs), 1344(vs), 1303(s), 1056(w), 986(m), 811(m), 604(m), 561(m), 505(w), 415(w).

Anal. Calcd (\%) for $\left(\mathrm{Et}_{2} \mathrm{NH}_{2}\right)_{3}\left[\mathrm{Cr}\left(\mathrm{Br}_{2} \mathrm{An}\right)_{3}\right]: \mathrm{C}, 31.01 ; \mathrm{H}, 3.12 ; \mathrm{N}$, 3.62\%. Found: C, 30.53; H, 3.04; N, 3.74\%.

Synthesis of $\left[(\mathrm{Et})(\mathrm{i}-\mathrm{Pr})_{2} \mathrm{NH}\right]_{3}\left[\mathrm{Cr}\left(\mathrm{Br}_{2} \mathrm{An}\right)_{3}\right]$. Bromanilic acid $(1 \mathrm{~g}$, $3.3 \mathrm{mmol}$ ) of bromanilic acid was dissolved in $40 \mathrm{~mL}$ of acetonitrile, and $1.94 \mathrm{~mL}(11.1 \mathrm{mmol})$ of $\mathrm{N}, \mathrm{N}$-diisopropylethylamine and $800 \mathrm{mg}$ $(1.6 \mathrm{mmol})$ of $\mathrm{KCr}\left(\mathrm{SO}_{4}\right)_{2} \cdot 12 \mathrm{H}_{2} \mathrm{O}$ dissolved in $20 \mathrm{~mL}$ of water were added to the solution. The solution was refluxed overnight and filtered. After 4 days, a dark red crystalline precipitate was obtained and collected by filtration. FT-IR $\left(\nu / \mathrm{cm}^{-1}, \mathrm{KBr}\right.$ pellets): $3448(\mathrm{~m})$, 3052(m), 2986(m), 2939(w), 2873(w), 2822(w), 2775(w), 2711(w), 1643(m), 1519(vs), 1344(vs), 1298(s), 1179(w), 1129(w), $1066(\mathrm{w}), 984(\mathrm{~m}), 809(\mathrm{~m}), 598(\mathrm{~m}), 559(\mathrm{~m}), 503(\mathrm{w}), 404(\mathrm{w})$.

Anal. Calcd (\%) for $\left[(\mathrm{Et})(\mathrm{i}-\mathrm{Pr})_{2} \mathrm{NH}\right]_{3}\left[\mathrm{Cr}^{\mathrm{II}}\left(\mathrm{Br}_{2} \mathrm{An}\right)_{3}\right]: \mathrm{C}, 37.92 ; \mathrm{H}$, 4.55; N, 3.16\%. Found: C, 37.63; H, 4.51; N, 3.22\%.

Synthesis of $\left(\mathrm{Me}_{2} \mathrm{NH}_{2}\right)\left[\mathrm{Mn}^{\prime \prime} \mathrm{Cr}^{\prime \prime \prime}\left(\mathrm{Br}_{2} \mathrm{An}\right)_{3}\right] \cdot 2 \mathrm{H}_{2} \mathrm{O}$ (1), $\left(\mathrm{Et}_{2} \mathrm{NH}_{2}\right)$ $\left[\mathrm{Mn}^{\prime \prime} \mathrm{Cr}^{\prime \prime \prime}\left(\mathrm{Br}_{2} \mathrm{An}\right)_{3}\right](2),\left(\mathrm{Et}_{3} \mathrm{NH}\right)\left[\mathrm{Mn}^{\prime \prime} \mathrm{Cr}^{\prime \prime \prime}\left(\mathrm{Cl}_{2} \mathrm{An}\right)_{3}\right](3)$, and [( $\left.\mathrm{Et}\right)(\mathrm{i}-$ $\left.\mathrm{Pr})_{2} \mathrm{NH}\right]\left[\mathrm{CrMn}\left(\mathrm{Br}_{2} \mathrm{An}\right)_{3}\right] \cdot\left(\mathrm{CHCl}_{3}\right)_{0.5} \cdot\left(\mathrm{H}_{2} \mathrm{O}\right)$ (4). Single crystals were obtained by a slow diffusion of a $5 \times 10^{-3} \mathrm{M}$ solution of $\mathrm{MnCl}_{2} \cdot 4 \mathrm{H}_{2} \mathrm{O}$ in $\mathrm{MeOH} / \mathrm{CH}_{2} \mathrm{Cl}_{2}$ 1:9 (2 and 3) or $\mathrm{MeOH} / \mathrm{CHCl}_{3} 1: 9$ (1 and 4) and a $5 \times 10^{-3} \mathrm{M}$ solution of $\left(\mathrm{Me}_{2} \mathrm{NH}_{2}\right)_{3}\left[\mathrm{Cr}^{\mathrm{III}}\left(\mathrm{Br}_{2} \mathrm{An}\right)_{3}\right] \cdot 2 \mathrm{H}_{2} \mathrm{O}$, $\left(\mathrm{Et}_{2} \mathrm{NH}_{2}\right)_{3}\left[\mathrm{Cr}^{\mathrm{III}}\left(\mathrm{Br}_{2} \mathrm{An}\right)_{3}\right], \quad\left(\mathrm{Et}_{3} \mathrm{NH}\right)_{3}\left[\mathrm{Cr}\left(\mathrm{Cl}_{2} \mathrm{An}\right)_{3}\right] \cdot \mathrm{H}_{2} \mathrm{O}$ or $[(\mathrm{Et})(\mathrm{i}-$ $\left.\mathrm{Pr})_{2} \mathrm{NH}\right]_{3}\left[\mathrm{Cr}\left(\mathrm{Br}_{2} \mathrm{An}\right)_{3}\right]$ in $\mathrm{MeOH}$. After several weeks, black crystals were obtained. Powder samples were obtained by mixing quickly the two solutions with $\mathrm{MnCl}_{2} \cdot 4 \mathrm{H}_{2} \mathrm{O}$ dissolved in $\mathrm{MeOH}$.

Anal. Calcd (\%) for 1, $\mathrm{C}_{20} \mathrm{H}_{12} \mathrm{Br}_{6} \mathrm{CrMnNO}_{14}$ : C 22.31, H 1.12, N 1.30. Found: C 21.89, H 1.32, N 1.29. Anal. Calcd (\%) for 2, $\mathrm{C}_{22} \mathrm{H}_{12} \mathrm{Br}_{6} \mathrm{CrMnNO}_{12}$ : C 24.73, H 1.13, N 1.31. Found: C 23.05, H 1.13, N 1.19. Anal. Calcd (\%) for 3, $\mathrm{C}_{24} \mathrm{H}_{16} \mathrm{Cl}_{6} \mathrm{CrMnNO}_{12}$ : C 34.73, $\mathrm{H}$ 1.94, N 1.69. Found: C 34.25, H 2.07, N 1.79. Anal. Calcd (\%) for 4, 
Table 1. Crystallographic Data for Compounds 1, 2, 3, and 4

\begin{tabular}{|c|c|c|c|c|}
\hline compound & 1 & 2 & 3 & 4 \\
\hline empirical formula & $\mathrm{C}_{20} \mathrm{H}_{12} \mathrm{Br}_{6} \mathrm{CrMnNO}_{14}$ & $\mathrm{C}_{22} \mathrm{H}_{12} \mathrm{Br}_{6} \mathrm{CrMnNO}_{12}$ & $\mathrm{C}_{24} \mathrm{H}_{16} \mathrm{Cl}_{6} \mathrm{CrMnNO}_{12}$ & $\mathrm{C}_{53} \mathrm{H}_{45} \mathrm{Br}_{12} \mathrm{Cl}_{3} \mathrm{Cr}_{2} \mathrm{Mn}_{2} \mathrm{~N}_{2} \mathrm{O}_{26}$ \\
\hline formula weight & 1040.62 & 1068.63 & 829.89 & 2397.70 \\
\hline crystal color & black & black & black & black \\
\hline crystal size & $0.09 \times 0.03 \times 0.02$ & $0.12 \times 0.07 \times 0.03$ & $0.06 \times 0.02 \times 0.01$ & $0.13 \times 0.10 \times 0.06$ \\
\hline temp $(\mathrm{K})$ & $120(2)$ & $120(2)$ & $180(2)$ & $120(2)$ \\
\hline wavelength $(\AA)$ & 0.71073 & 0.71073 & 1.54184 & 0.71073 \\
\hline crystal system & trigonal & trigonal & trigonal & trigonal \\
\hline space group & $P-31 c$ & $P-31 c$ & $P-31 c$ & $P-3 c 1$ \\
\hline$a(\AA)$ & $13.7524(8)$ & $13.7058(7)$ & $13.6939(15)$ & $13.7008(6)$ \\
\hline$c(\AA)$ & $9.3395(7)$ & $9.4887(6)$ & $9.1823(8)$ & $26.366(2)$ \\
\hline$\gamma(\operatorname{deg})$ & 120 & 120 & 120 & 120 \\
\hline$V\left(\AA^{3}\right)$ & $1529.7(2)$ & $1543.6(2)$ & $1491.2(4)$ & $4286.1(6)$ \\
\hline$\rho_{\text {calc }}\left(\mathrm{Mg} / \mathrm{m}^{3}\right)$ & 2.242 & 2.273 & 1.813 & 1.828 \\
\hline$\mu(\operatorname{Mo~K} \alpha)\left(\mathrm{mm}^{-1}\right)$ & 8.660 & 8.585 & 11.979 & 6.287 \\
\hline$\theta$ range $(\mathrm{deg})$ & $3.421-27.511$ & $3.433-27.544$ & $3.727-70.320$ & $3.351-26.446$ \\
\hline reflns collected & 33285 & 28079 & 4509 & 84273 \\
\hline independent reflns $\left(R_{\text {int }}\right)$ & $1181(0.1682)$ & $1194(0.0845)$ & $719(0.0510)$ & $2122(0.1493)$ \\
\hline L. S. parameters, $p /$ restraints, $r$ & $65 / 2$ & $69 / 0$ & $75 / 0$ & $150 / 10$ \\
\hline$R 1(F),{ }^{a} I>2 \sigma(I)$ & 0.1210 & 0.1662 & 0.0689 & 0.1988 \\
\hline$w R 2\left(F^{2}\right),{ }^{b}$ all data & 0.3456 & 0.2672 & 0.1985 & 0.4377 \\
\hline$S\left(F^{2}\right){ }^{c}$ all data & 1.073 & 1.204 & 1.090 & 1.142 \\
\hline
\end{tabular}

$\mathrm{C}_{53} \mathrm{H}_{45} \mathrm{Br}_{12} \mathrm{Cl}_{3} \mathrm{Cr}_{2} \mathrm{Mn}_{2} \mathrm{~N}_{2} \mathrm{O}_{26}$ : C 26.47, $\mathrm{H}$ 1.89, N 1.16. Found: $\mathrm{C}$ 26.58, H 2.07, N 1.08.

Structural Characterization. Single crystals of the four compounds were mounted on glass fibers using a viscous hydrocarbon oil to coat the crystal and then transferred directly to the cold nitrogen stream for data collection. All reflection data were collected at $120 \mathrm{~K}$ for 1,2 , and 4 and $180 \mathrm{~K}$ for 3 , on a Supernova diffractometer equipped with a graphite-monochromated Enhance (Mo) X-ray Source $(\lambda=0.7107 \AA)(1,2$, and 4$)$ and on a Supernova Atlas Dual Source diffractometer with a Cu X-ray source $(\lambda=1.54184 \AA)$ (3). The CrysAlisPro program, Oxford Diffraction Ltd., was used for unit cell determinations and data reduction. Empirical absorption correction was performed using spherical harmonics, implemented in the SCALE3 ABSPACK scaling algorithm. Crystal structures were solved by direct methods with the SIR97 program $^{20}$ and refined against all $F^{2}$ values with the SHELXL-2013 program $^{21}$ using the WinGX graphical user interface. ${ }^{22}$ All non-hydrogen atoms were refined anisotropically except for disordered solvent molecules and countercations. Due to this disorder, the overall quality of the data of 1,2 , and 4 is poor, and this results in high $\mathrm{R}$ factors $(0.121,0.166$, and 0.199 , respectively). Hydrogen atoms for disordered alkylammonium cations and disordered chloroform or water molecules in $\mathbf{4}$ and water molecules in $\mathbf{1}$ were not introduced but are taken into account in the chemical formulas. Data collection and refinement statistics are collected in Table 1. CCDC 1564529, 1564530, 1491090, and 1491091 contain the supplementary crystallographic data for this paper. These data can be obtained free of charge from The Cambridge Crystallographic Data Centre via www.ccdc.cam.ac.uk/data_request/ cif. Glass capillaries $(0.5 \mathrm{~mm})$ were filled with polycrystalline samples of the compounds and mounted and aligned on a Empyrean PANalytical powder diffractometer, using $\mathrm{Cu} \mathrm{K} \alpha$ radiation ( $\lambda=$ $1.54177 \AA$ ). A total of three scans were collected at room temperature in the $2 \theta$ range $2-40^{\circ}$. To check the stability of samples after proton conductivity measurements, powder X-ray diffraction (PXRD) patterns were collected using a Bragg-Brentano configuration in the $2 \theta$ range of $4-50^{\circ}$. Additionally, in order to prove the recrystallization of compound 4 in the presence of solvent molecules, a transmission geometry was selected. For this study, a small amount of $\mathbf{4}$ was placed in a holder between two Kapton films and some drops of a $\mathrm{MeOH}$ / $\mathrm{CHCl}_{3}$ mixture were added. The powder diffraction pattern of the resolvated sample was recorded on an Empyrean PANalytical powder diffractometer equipped with a $\theta / \theta$ goniometer and $\mathrm{Cu} \mathrm{K} \alpha$ radiation in the $2 \theta$ range of $5-50^{\circ}$.

Physical Measurements. Magnetic measurements were performed with a Quantum Design MPMS-XL-5 SQUID magnetometer and a Quantum Design PPMS on crystalline samples of $1(2.2 \mathrm{mg}), 2$ $(9.5 \mathrm{mg}), 3(5.5 \mathrm{mg})$, and $4(7.2 \mathrm{mg})$. Crystals of 4 were measured first in contact with the mother liquor (solvated sample). Afterward, the solvent was removed and the magnetic measurements were performed in the dry sample. Finally, to check the reversibility, the crystals were reimmersed in a $\mathrm{MeOH} / \mathrm{CHCl}_{3}$ mixture overnight and the measurements were repeated in contact with the solvent mixture (resolvated sample). The $\mathrm{Mn} / \mathrm{Cr} / \mathrm{X}(\mathrm{X}=\mathrm{Cl}$ or $\mathrm{Br})$ ratios were measured with a Philips ESEM X230 scanning electron microscope equipped with an EDAX DX-4 microsonde.

Conductivity Characterization. Impedance data were collected on cylindrical pellet ( $5 \mathrm{~mm}$ of diameter and $\sim 1 \mathrm{~mm}$ of thickness) obtained by pressing $30-40 \mathrm{mg}$ of powder samples of 1-4 at 250 $\mathrm{MPa}$, for $2 \mathrm{~min}$. The pellets were pressed between porous $\mathrm{C}$ electrodes (Sigracet, GDL $10 \mathrm{BB}$, no Pt). The sample cells were places inside a temperature and humidity controlled chamber (Espec SH-222) and connected to a HP4284A impedance analyzer. AC impedance data were collected over the frequency range from $20 \mathrm{~Hz}$ to $1 \mathrm{MHz}$ with an applied voltage of $1 \mathrm{~V}$. All measurements were electronically controlled by the winDETA package of programs. ${ }^{23}$ Pellets were first equilibrated at $95 \%$ relative humidity $(\mathrm{RH})$ and preheated $\left(0.2^{\circ} \mathrm{C} / \mathrm{min}\right)$ from 25 to $70{ }^{\circ} \mathrm{C}$. Impedance spectra were recorded on cooling using a stabilization time of $3 \mathrm{~h}$ from 70 to $25{ }^{\circ} \mathrm{C}\left(0.2{ }^{\circ} \mathrm{C} / \mathrm{min}\right)$ at $10^{\circ} \mathrm{C}$ intervals. Water condensation on sample was avoided by reducing first the relative humidity before decreasing temperature.

\section{RESULTS AND DISCUSSION}

Syntheses. The preparation of $\left(\mathrm{Me}_{2} \mathrm{NH}_{2}\right)$ $\left[\mathrm{Mn}^{\mathrm{II}} \mathrm{Cr}^{\mathrm{III}}\left(\mathrm{Br}_{2} \mathrm{An}\right)_{3}\right] \cdot 2 \mathrm{H}_{2} \mathrm{O}(\mathbf{1}),\left(\mathrm{Et}_{2} \mathrm{NH}_{2}\right)\left[\mathrm{Mn}^{\mathrm{II}} \mathrm{Cr}^{\mathrm{III}}\left(\mathrm{Br}_{2} \mathrm{An}\right)_{3}\right]$ (2), $\left(\mathrm{Et}_{3} \mathrm{NH}\right)\left[\mathrm{Mn}^{\mathrm{II}} \mathrm{Cr}^{\mathrm{III}}\left(\mathrm{Cl}_{2} \mathrm{An}\right)_{3}\right](3)$, and $\left[(\mathrm{Et})(\mathrm{i}-\mathrm{Pr})_{2} \mathrm{NH}\right]-$ $\left[\mathrm{Mn}^{\mathrm{II}} \mathrm{Cr}^{\mathrm{II}}\left(\mathrm{Br}_{2} \mathrm{An}\right)_{3}\right] \cdot\left(\mathrm{CHCl}_{3}\right)_{0.5} \cdot\left(\mathrm{H}_{2} \mathrm{O}\right)$ (4) is based on the slow diffusion of solutions of the anilate precursor salts $\left(\mathrm{Me}_{2} \mathrm{NH}_{2}\right)_{3}\left[\mathrm{Cr}^{\mathrm{III}}\left(\mathrm{Br}_{2} \mathrm{An}\right)_{3}\right] \cdot 2 \mathrm{H}_{2} \mathrm{O}(\mathbf{1}),\left(\mathrm{Et}_{2} \mathrm{NH}_{2}\right)_{3}\left[\mathrm{Cr}\left(\mathrm{Br}_{2} \mathrm{An}\right)_{3}\right]$ (2), $\left(\mathrm{Et}_{3} \mathrm{NH}\right)_{3}\left[\mathrm{Cr}^{\mathrm{III}}\left(\mathrm{Cl}_{2} \mathrm{An}\right)_{3}\right](3)$, and $[(\mathrm{Et})(\mathrm{i}-$ $\left.\mathrm{Pr})_{2} \mathrm{NH}\right]_{3}\left[\mathrm{Cr}^{\mathrm{III}}\left(\mathrm{Br}_{2} \mathrm{An}\right)_{3}\right]$ (4) into a $\mathrm{Mn}^{2+}$ solution in other solvent. This method is simpler than that used to prepare other 
2D bimetallic anilate-based networks containing cationic $\mathrm{Fe}(\mathrm{III})$ Schiff-base complexes for which $\left[\mathrm{Cr}^{\mathrm{III}}\left(\mathrm{Cl}_{2} \mathrm{An}\right)_{3}\right]^{3-}$ or $\left[\mathrm{Cr}^{\mathrm{III}}\left(\mathrm{Br}_{2} \mathrm{An}\right)_{3}\right]^{3-}$ salts were not known. ${ }^{13,14}$ The best results were obtained with methanol/dichloromethane (1 and 3 ) or methanol/chloroform (2 and 4) mixtures to dissolve the $\mathrm{Mn}^{2+}$ salt, and methanol to dissolve the anilate precursor. The chemical composition of these compounds, checked by microanalysis, shows $\mathrm{Mn} / \mathrm{Cr} / \mathrm{Cl}$ (3) or $\mathrm{Mn} / \mathrm{Cr} / \mathrm{Br}$ (1, 2, and 4) ratios close to the expected $1 / 1 / 6$. Composition obtained by elemental analysis of $\mathbf{1}$ is consistent with the presence of two water molecules. The weight loss corresponding to these water molecules is in agreement with the $3.5 \%$ weight loss below 140 ${ }^{\circ} \mathrm{C}$ observed in TGA of this compound (see below), which is not shown by the other three compounds. Composition of $\mathbf{2}$ obtained by elemental analysis deviates slightly from the theoretical composition. This could suggest the presence of an amorphous impurity or a solvated phase in the polycrystalline sample, which are not detected by PXRD. Synthesis of $\mathbf{1}, \mathbf{2}$, and 3 could be performed by mixing methanolic solutions of $\left(\mathrm{Me}_{2} \mathrm{NH}_{2}\right)_{3}\left[\mathrm{Cr}{ }^{\mathrm{III}}\left(\mathrm{Br}_{2} \mathrm{An}\right)_{3}\right] \cdot 2 \mathrm{H}_{2} \mathrm{O}(\mathbf{1}),\left(\mathrm{Et}_{2} \mathrm{NH}_{2}\right)_{3}\left[\mathrm{Cr}\left(\mathrm{Br}_{2} \mathrm{An}\right)_{3}\right]$ (2), or $\left(\mathrm{Et}_{3} \mathrm{NH}\right)_{3}\left[\mathrm{Cr}^{\mathrm{II}}\left(\mathrm{Cl}_{2} \mathrm{An}\right)_{3}\right]$ (3) and $\mathrm{MnCl}_{2}$. PXRD pattern confirms that these powders are isostructural with the single crystals (see below). In the case of 4 , the same direct precipitation method led to a product with a PXRD pattern completely different to that of the single crystals.

Structures of 1, 2, and 3. The three compounds crystallize in the trigonal space group $P-31 c$. The structure is formed by anionic 2D anilate-based layers in the $a b$ plane of formula $\left[\mathrm{Mn}^{\mathrm{II}} \mathrm{Cr}^{\mathrm{III}}\left(\mathrm{Br}_{2} \mathrm{An}\right)_{3}\right]^{-}(1$ and 2$)$ or $\left[\mathrm{Mn}^{\mathrm{II}} \mathrm{Cr}^{\mathrm{III}}\left(\mathrm{Cl}_{2} \mathrm{An}\right)_{3}\right]^{-}$(3) with the well-known honeycomb structure, which is similar to that reported in other bimetallic anilate-based compounds. ${ }^{12-14}$ It consists in a hexagonal layer where the $\mathrm{Cr}$ (III) and $\mathrm{Mn}$ (II) ions occupy alternating vertices of the hexagons and are linked through $\mathrm{X}_{2} \mathrm{An}$ bridges in such a way that each $\mathrm{Mn}$ (II) is surrounded by three neighboring $\mathrm{Cr}$ (III) and vice versa (see Figure 1). It contains crystallographically independent $\mathrm{Mn}$ and $\mathrm{Cr}$ ions with occupancies of 0.16667 and characteristic $\mathrm{Mn}-\mathrm{O}$ and $\mathrm{Cr}-\mathrm{O}$ distances $(2.208(10)$ and $1.972(8) \AA$ in $\mathbf{1}$, 2.171(14) and 1.963(9) $\AA$ in 2, and 2.174(4) and 1.964(4) $\AA$ in 3). Within the honeycomb layer, the bridged $\mathrm{Mn}$ (II) and $\mathrm{Cr}$ (III) present the opposite chirality, as expected. $\mathrm{Mn}$ (II) and $\mathrm{Cr}$ (III) centers are situated on a site of crystallographic 3-fold symmetry, with three $\mathrm{Br}_{2} \mathrm{An}$ or $\mathrm{Cl}_{2} \mathrm{An}$ related in a propeller-like arrangement. Due to the centrosymmetric character of the structure, $\mathrm{Mn}(\mathrm{II})$ and $\mathrm{Cr}(\mathrm{III})$ present the opposite configuration in neighboring layers. These layers are alternated due to the presence of an inversion center between $\mathrm{Mn}$ ions from different layers that give rise to two possible dispositions of the neighboring layers (see Figure S1).

As recently found by us in the structures of $2 \mathrm{D}$ anilate-based compounds obtained with small templating cations such as $\left[\mathrm{Fe}^{\mathrm{III}}\left(\mathrm{acac}_{2} \text {-trien }\right)\right]^{+,}{ }^{14} \mathrm{Me}_{2} \mathrm{NH}_{2}{ }^{+}$cations of $\mathbf{1}, \mathrm{Et}_{2} \mathrm{NH}_{2}{ }^{+}$cations of 2 , and $\mathrm{Et}_{3} \mathrm{NH}^{+}$cations of 3 are inserted into the hexagons of the $2 \mathrm{D}$ anilate-based network and not between the layers as in most of the previous oxalate or anilate-based 2D compounds (see Figure 2). Thus, in 3 the center of the hexagons is occupied by the $\mathrm{N}$ of a crystallographically independent $\mathrm{Et}_{3} \mathrm{NH}^{+}$cation (N1) with an occupancy of 0.16667 as it is placed in a 3-fold axis (see Figure 1). On the other hand, N1 and the methylene $\mathrm{C}$ atom $(\mathrm{C} 4)$ of $\left(\mathrm{Et}_{3} \mathrm{NH}\right)^{+}$cation are placed in the same 2-fold axis perpendicular to the 3-fold axis mentioned before. Consequently, the methyl $\mathrm{C}$ atom (C5) of $\left(\mathrm{Et}_{3} \mathrm{NH}\right)^{+}$cation presents a disorder between two different
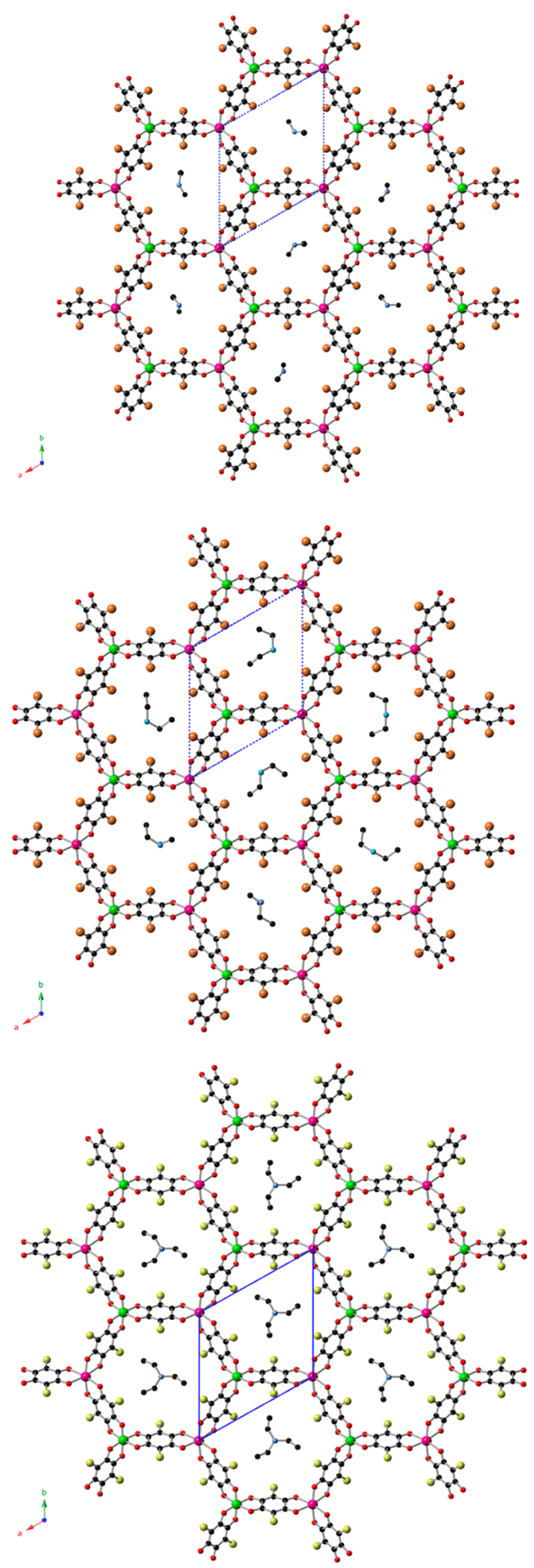

Figure 1. Projection in the $a b$ plane of the compounds $\left(\mathrm{Me}_{2} \mathrm{NH}_{2}\right)$ $\left[\mathrm{Mn}^{\mathrm{II}} \mathrm{Cr}^{\mathrm{III}}\left(\mathrm{Br}_{2} \mathrm{An}\right)_{3}\right] \cdot 2 \mathrm{H}_{2} \mathrm{O}$ (1) (top), $\left(\mathrm{Et}_{2} \mathrm{NH}_{2}\right)\left[\mathrm{Mn}^{\mathrm{II}} \mathrm{Cr}^{\mathrm{III}}\left(\mathrm{Br}_{2} \mathrm{An}\right)_{3}\right]$ (2) (middle), and $\left(\mathrm{Et}_{3} \mathrm{NH}\right)\left[\mathrm{Mn}^{\mathrm{II}} \mathrm{Cr}^{\mathrm{III}}\left(\mathrm{Cl}_{2} \mathrm{An}\right)_{3}\right]$ (3) (bottom). (Cr (green), Mn (pink) C (black), N (blue), O (red), Br (brown), Cl (yellow). Part of the disordered methylene or methyl groups of $\mathrm{Me}_{2} \mathrm{NH}_{2}{ }^{+}, \mathrm{Et}_{2} \mathrm{NH}_{2}{ }^{+}$, or $\mathrm{Et}_{3} \mathrm{NH}^{+}$have been omitted for clarity.

configurations with occupancies of 0.5 . The $\mathrm{N}$ atoms from $\mathrm{Et}_{3} \mathrm{NH}^{+}$cations are placed below and above the $\mathrm{Cr}$ atoms from the two neighboring layers. The smaller size of $\mathrm{Me}_{2} \mathrm{NH}_{2}{ }^{+}$and 

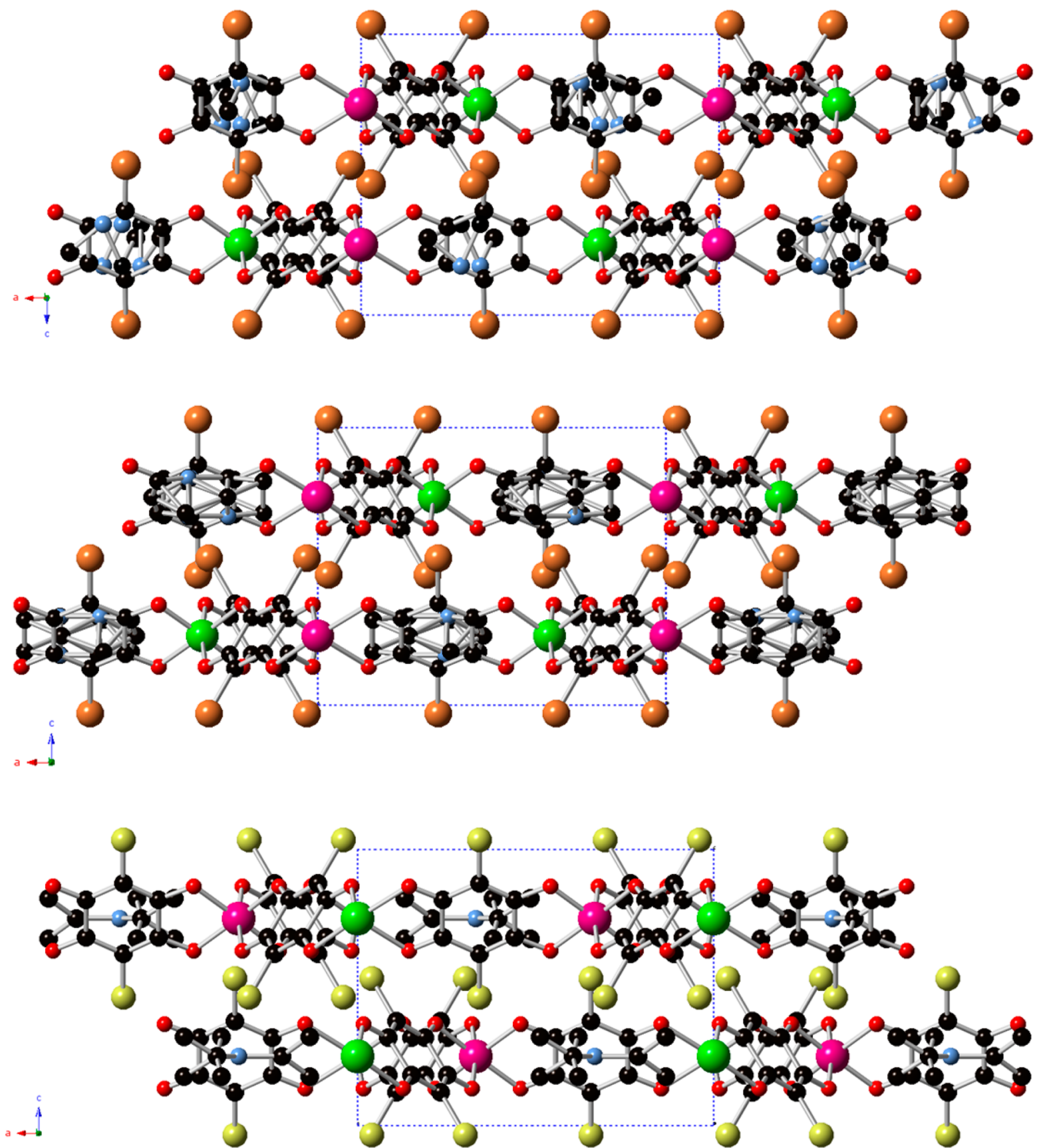

Figure 2. Projection in the ac plane of the compounds $\left(\mathrm{Me}_{2} \mathrm{NH}_{2}\right)\left[\mathrm{Mn}^{\mathrm{II}} \mathrm{Cr}^{\mathrm{III}}\left(\mathrm{Br}_{2} \mathrm{An}\right)_{3}\right] \cdot 2 \mathrm{H}_{2} \mathrm{O}$ (1) (top), $\left(\mathrm{Et}_{2} \mathrm{NH}_{2}\right)\left[\mathrm{Mn}^{\mathrm{II}} \mathrm{Cr}^{\mathrm{III}}\left(\mathrm{Br}_{2} \mathrm{An}\right)_{3}\right]$ (2) (middle), and $\left(\mathrm{Et}_{3} \mathrm{NH}\right)\left[\mathrm{Mn}^{\mathrm{II}} \mathrm{Cr}^{\mathrm{III}}\left(\mathrm{Cl}_{2} \mathrm{An}\right)_{3}\right]$ (3) (bottom). (Cr (green), Mn (pink) C (black), N (blue), O (red), Cl (yellow), and Br (brown)). Part of the disordered methyl groups of $\left(\mathrm{Me}_{2} \mathrm{NH}_{2}\right)^{+}$have been omitted for clarity.

$\mathrm{Et}_{2} \mathrm{NH}_{2}{ }^{+}$cations of $\mathbf{1}$ and 2 with respect to $\mathrm{Et}_{3} \mathrm{NH}^{+}$ones of 3, gives rise to a higher degree of disorder. To solve it, $\mathrm{Me}_{2} \mathrm{NH}_{2}{ }^{+}$ cations of $\mathbf{1}$ have been modeled with three atoms with occupancies of $0.16667(\mathrm{~N}, \mathrm{C} 4$, and C5) with two of them, $\mathrm{N}$ and $\mathrm{C} 4$, occupying the same position. On the other hand, $\mathrm{Et}_{2} \mathrm{NH}_{2}{ }^{+}$cations of 2 have been modeled with four atoms with occupancies of $0.16667(\mathrm{~N}, \mathrm{C} 100$ and $\mathrm{C} 101)$ and 0.33333 (C102) with two of them, $\mathrm{N}$ and C100, occupying the same position. The disordered $\mathrm{Me}_{2} \mathrm{NH}_{2}{ }^{+}$of $\mathbf{1}$ and $\mathrm{Et}_{2} \mathrm{NH}_{2}{ }^{+}$of $\mathbf{2}$ are generated from these atoms by a 3-fold axis in the middle of the hexagons perpendicular to the anilate-based layers and three 2 fold axis perpendicular to it.
The minimum distances between metals of neighboring layers are $4.67 \AA$ for $1,4.74 \AA$ for 2 and $4.59 \AA$ for 3, much shorter than those of compounds with $\left[\mathrm{Fe}^{\mathrm{III}}\left(\mathrm{acac}_{2} \text {-trien }\right)\right]^{+}$ $(7.39 \AA)$. This is a consequence of the smaller size of $\mathrm{Me}_{2} \mathrm{NH}_{2}{ }^{+}, \mathrm{Et}_{2} \mathrm{NH}_{2}{ }^{+}$, and $\mathrm{Et}_{3} \mathrm{NH}^{+}$cations, which permits a larger degree of interpenetration between neighboring layers, and the alternated disposition of these layers. The higher interlayer distances of $\mathbf{1}$ and $\mathbf{2}$ compared with that of $\mathbf{3}$ are due to the presence of $\mathrm{Br}$ instead of $\mathrm{Cl}$. As expected, these distances are much shorter than those reported in the bimetallic 2D anilate-based compounds with the templating cations $\mathrm{NBu}_{4}^{+}$ $(9.69 \AA),\left[\left(\mathrm{H}_{3} \mathrm{O}\right)(\mathrm{phz})_{3}\right]^{+}(9.03-9.21 \AA)$ or $\left[\mathrm{Fe}^{\mathrm{III}}\left(\mathrm{sal}_{2} \text {-trien }\right)\right]^{+}$ and derivatives $(11.06-11.92 \AA)$ between the layers. ${ }^{12-14}$ 
The structure of 1 resembles those of $\left(\mathrm{Me}_{2} \mathrm{NH}_{2}\right)_{2}\left[\mathrm{Fe}^{\mathrm{III}}{ }_{2}\left(\mathrm{~L}_{1}\right)_{3}\right] \cdot 2 \mathrm{H}_{2} \mathrm{O} \cdot 6 \mathrm{D} \mathrm{MF},{ }^{16}$ $\left(\mathrm{Me}_{2} \mathrm{NH}_{2}\right)_{3}\left[\mathrm{Al}_{4}\left(\mathrm{~L}_{2}\right)_{3}\left(\mathrm{~L}_{1} \bullet\right)_{3}\right] \cdot 3 \mathrm{D} \mathrm{MF}$ a n d $\left(\mathrm{Me}_{2} \mathrm{NH}_{2}\right)_{3}\left[\mathrm{Al}_{4}\left(\mathrm{~L}_{1}\right)_{3}\left(\mathrm{~L}_{1} \bullet\right)_{3}\right] \cdot 9 \mathrm{DMF}^{24}\left(\mathrm{~L}_{1}\right.$ and $\mathrm{L}_{1} \bullet$, oxidized and reduced forms of $\mathrm{Cl}_{2} \mathrm{An}$ and $\mathrm{L}_{2}$ and $\mathrm{L}_{2} \bullet$, oxidized and reduced forms of 2,5-dihydroxy-1,4-benzoquinone). Indeed, a and $b$ parameters of these compounds are very close to those of 1,2 , and 3 indicating that the $2 \mathrm{D}$ layers have a very similar structure. However, neighboring anilate layers in these compounds are eclipsed defining channels as in other homometallic and heterometallic 2D anilate-based compounds. ${ }^{12,25}$ Furthermore, the higher number of $\mathrm{Me}_{2} \mathrm{NH}_{2}^{+}$ cations, needed to compensate the higher charge of the anilate-based layers in these compounds, occupy the interlamellar space and not the center of the hexagons as those of $\mathbf{1}$, 2, and 3. This leads to longer interlayer distances 8.7449(5) $\AA$ for $\left(\mathrm{Me}_{2} \mathrm{NH}_{2}\right)_{2}\left[\mathrm{Fe}^{\mathrm{III}}{ }_{2}\left(\mathrm{~L}_{1}\right)_{3}\right] \cdot 2 \mathrm{H}_{2} \mathrm{O} \cdot 6 \mathrm{DMF}{ }^{16} 8.7701(2) \AA$ for $\left(\mathrm{Me}_{2} \mathrm{NH}_{2}\right)_{3}\left[\mathrm{Al}_{4}\left(\mathrm{~L}_{2}\right)_{3}\left(\mathrm{~L}_{1} \bullet\right)_{3}\right] \cdot 3 \mathrm{DMF}$ and $8.7473(5) \AA$ for $\left(\mathrm{Me}_{2} \mathrm{NH}_{2}\right)_{3}\left[\mathrm{Al}_{4}\left(\mathrm{~L}_{1}\right)_{3}\left(\mathrm{~L}_{1} \bullet\right)_{3}\right] \cdot 9 \mathrm{DMF}{ }^{24}$ Similar structures have been obtained very recently with the homometallic compounds $\left(\mathrm{Et}_{4} \mathrm{~N}\right)_{2}\left[\mathrm{M}_{2}\left(\mathrm{Cl}_{2} \mathrm{An}\right)_{3}\right](\mathrm{M}=\mathrm{Mg}, \mathrm{Mn}, \mathrm{Fe}, \mathrm{Co}, \mathrm{Ni}, \mathrm{Cu}$, and $\mathrm{Zn})$ and $\left(\mathrm{Et}_{4} \mathrm{~N}\right)_{2}\left[\mathrm{Zn}_{2}\left(\mathrm{~F}_{2} \mathrm{An}\right)_{3}\right]$ with $\mathrm{Et}_{4} \mathrm{~N}^{+}$cations occupying the space between the $\left[\mathrm{Zn}_{2}\left(\mathrm{~F}_{2} \mathrm{An}\right)_{3}\right]^{2-}$ layers. ${ }^{26}$

The presence of the alkylammonium cations in the center of the hexagons together with the eclipsed disposition of the layers gives rise to the isolation of the cations in the structures. Thus, $\mathrm{N} \cdots \mathrm{N}, \mathrm{N} \cdots \mathrm{O}$, and $\mathrm{N} \cdots \mathrm{X}(\mathrm{X}=\mathrm{Cl}, \mathrm{Br})$ distances in the three compounds are longer than $3.4 \AA$ leading to the absence of clear hydrogen bonding.

PXRD patterns of crystals of $\mathbf{1}$ and $\mathbf{2}$ at $300 \mathrm{~K}$ are shown in Figure S2. They confirm the structures obtained from single crystal X-ray diffraction experiments, although that of 1 presents some differences with the simulated one from the single crystal X-ray diffraction structure obtained at $120 \mathrm{~K}$, which could be related to the solvate water molecules. PXRD pattern of a sample of $\mathbf{1}$ obtained by mixing quickly the two precursor solutions fits very well to the simulated one (Figure S2). In the case of 3 , it was not possible to obtain enough crystalline sample for magnetic and proton conduction measurements (see below). As a result, these measurements were performed in a powder sample obtained in the same way as described for 1. PXRD pattern of this sample confirms the structure obtained from single crystal X-ray diffraction (see Figure S2).

Structure of $\left[(\mathrm{Et})(\mathrm{i}-\mathrm{Pr})_{2} \mathrm{NH}\right]\left[\mathrm{Mn}^{\mathrm{II}} \mathrm{Cr}^{\mathrm{III}}\left(\mathrm{Br}_{2} \mathrm{An}\right)_{3}\right] \cdot\left(\mathrm{CHCl}_{3}\right)_{0.5^{\circ}}$ $\left(\mathrm{H}_{2} \mathrm{O}\right)$ (4). This compound crystallizes in the trigonal space group $P-3 c 1$. The structure of 4 is formed by anionic $2 \mathrm{D}$ anilate-based layers in the $a b$ plane of formula $\left[\mathrm{Mn}^{\mathrm{II}} \mathrm{Cr}^{\mathrm{III}}\left(\mathrm{Br}_{2} \mathrm{An}\right)_{3}\right]^{-}$, which are very similar to those of $\mathbf{1}$ and 2 (Figure 3 ). However, the increase of size of the templating cation $\left(\left[(\mathrm{Et})(\mathrm{i}-\mathrm{Pr})_{2} \mathrm{NH}\right]^{+}\right)$with respect to those used in the previous compounds gives rise to important structural changes. Thus, a lateral view of the structure shows the presence of bilayers formed by two $\left[\mathrm{Mn}^{\mathrm{II}} \mathrm{Cr}^{\mathrm{III}}\left(\mathrm{Br}_{2} \mathrm{An}\right)_{3}\right]^{-}$ layers with a high degree of interpenetration, which is similar to that of 1, 2, and 3 (Figure 4). These bilayers are separated by a layer of disordered $\left[(\mathrm{Et})(\mathrm{i}-\mathrm{Pr})_{2} \mathrm{NH}\right]^{+}$cations and solvent molecules (disordered $\mathrm{CHCl}_{3}$ and $\mathrm{H}_{2} \mathrm{O}$ molecules). Consequently, there are two types of interlayer distances; intrabilayer ones $(\sim 4.42 \AA)$, which are similar to those of 1 , 2 , and 3 , and interbilayer ones $(\sim 8.76 \AA)$, which are similar to those of $\left(\mathrm{Me}_{2} \mathrm{NH}_{2}\right)_{2}\left[\mathrm{Fe}_{2}^{\mathrm{III}} \mathrm{L}_{3}\right] \cdot 2 \mathrm{H}_{2} \mathrm{O} \cdot 6 \mathrm{DMF}$. ${ }^{16}$ Another important difference is that only half of the hexagons of the

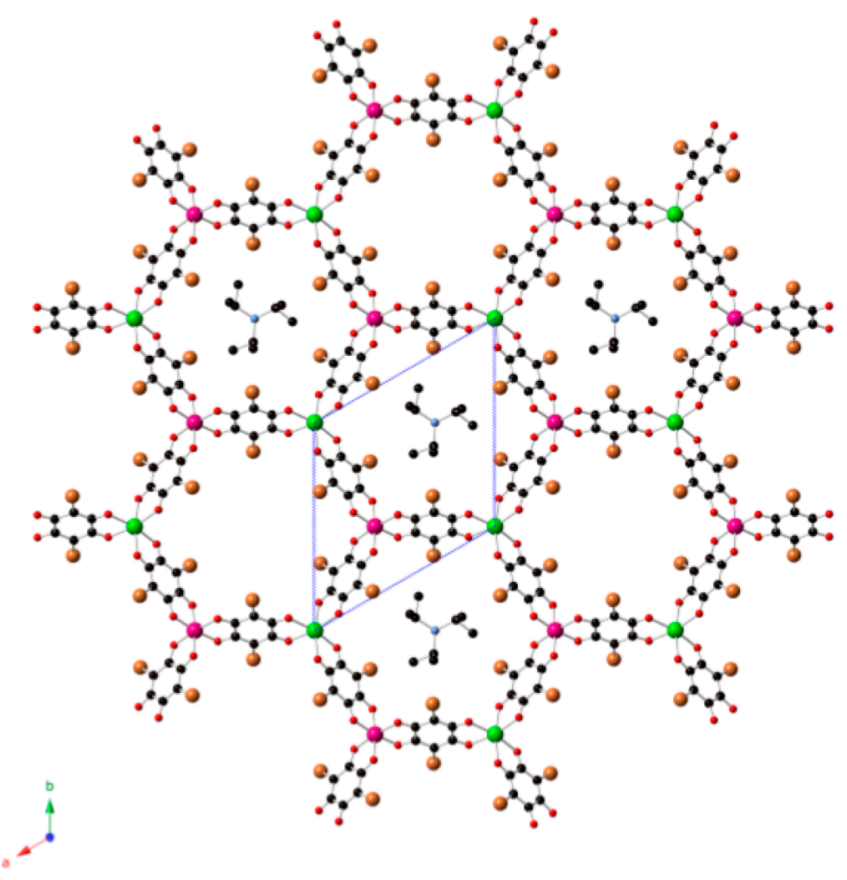

Figure 3. Projection in the $a b$ plane of the compound $[(\mathrm{Et})(\mathrm{i}-$ $\left.\mathrm{Pr})_{2} \mathrm{NH}\right]\left[\mathrm{Mn}^{\mathrm{II}} \mathrm{Cr}^{\mathrm{III}}\left(\mathrm{Br}_{2} \mathrm{An}\right)_{3}\right] \cdot\left(\mathrm{CHCl}_{3}\right)_{0.5} \cdot\left(\mathrm{H}_{2} \mathrm{O}\right)$ (4). (Cr (green), $\mathrm{Mn}$ (pink) C (black), N (blue), O (red), Br (brown)).

$\left[\mathrm{Mn}^{\mathrm{II}} \mathrm{Cr}^{\mathrm{III}}\left(\mathrm{Br}_{2} \mathrm{An}\right)_{3}\right]^{-}$layers are occupied by $\left[(\mathrm{Et})(\mathrm{i}-\mathrm{Pr})_{2} \mathrm{NH}\right]^{+}$ cations. The remaining cations, needed to compensate the charge, are placed between the bilayers. The presence of $\mathrm{CHCl}_{3}$ molecules is confirmed by microanalysis, which shows a $\mathrm{Mn}: \mathrm{Cr}: \mathrm{Cl}$ ratio close to $1: 1: 0.3$. The $\mathrm{Cl}$ content calculated by microanalysis is lower than that predicted from the structure ( $\mathrm{Mn}: \mathrm{Cr}: \mathrm{Cl}$ ratio of $1: 1: 1.5$ ) due to desolvation after extracting the crystals from the mother liquor.

The $\left[\mathrm{Mn}^{\mathrm{II}} \mathrm{Cr}^{\mathrm{III}}\left(\mathrm{Br}_{2} \mathrm{An}\right)_{3}\right]^{-}$layers contain crystallographically independent $\mathrm{Mn}$ and $\mathrm{Cr}$ ions with occupancies of 0.33333 and characteristic $\mathrm{Mn}-\mathrm{O}$ and $\mathrm{Cr}-\mathrm{O}$ distances (2.156(17)$2.182(16)$ and 1.983(14)-1.986(13) A, respectively). As in 1, 2 , and $3, \mathrm{Mn}(\mathrm{II})$ and $\mathrm{Cr}(\mathrm{III})$ centers are situated on a site of crystallographic 3 -fold symmetry, with three $\mathrm{Br}_{2} \mathrm{An}$ related in a propeller-like arrangement. Within the honeycomb layer, the bridged $\mathrm{Mn}(\mathrm{II})$ and $\mathrm{Cr}(\mathrm{III})$ present the opposite chirality, as expected (Figure 3). Due to the centrosymmetric character of the structure, $\mathrm{Mn}(\mathrm{II})$ and $\mathrm{Cr}(\mathrm{III})$ present the opposite configuration in neighboring layers belonging to the same bilayer. These two layers are alternated due to the presence of an inversion center between two Mn ions (see Figure S3). The neighboring $\left[\mathrm{Mn}^{\mathrm{II}} \mathrm{Cr}^{\mathrm{II}}\left(\mathrm{Br}_{2} \mathrm{An}\right)_{3}\right]^{-}$layers from different bilayers present halogen-halogen interactions ${ }^{27}$ involving half of $\mathrm{Br}$ atoms from $\mathrm{Br}_{2} \mathrm{An}$ ligands $(\mathrm{Br} 2)$ with minimum $\mathrm{Br} \cdots \mathrm{Br}$ interlayer distances of ca. $3.25 \AA$ (see Figure S4). These interactions are not present between neighboring layers belonging to the same bilayer and in 1,2 , and 3 .

As mentioned above, there are two crystallographically independent $\left[(\mathrm{Et})(\mathrm{i}-\mathrm{Pr})_{2} \mathrm{NH}\right]^{+}$cations. $\left[(\mathrm{Et})(\mathrm{i}-\mathrm{Pr})_{2} \mathrm{NH}\right]^{+}$ cations with $\mathrm{N} 2$ are inserted into the hexagons of the $2 \mathrm{D}$ anilate-based network as in $\mathbf{1}$ (see Figure 3), while those with $\mathrm{N} 1$ are placed in the interlayer space (see Figure S5). N1 and $\mathrm{N} 2$ present occupancies of 0.16667 . N2 is placed in the same 3fold axis as $\mathrm{Cr}$ ions. Disordered solvent molecules $\left(\mathrm{CHCl}_{3}\right.$ and $\mathrm{H}_{2} \mathrm{O}$ ) are placed in these interlayer space and give rise to 


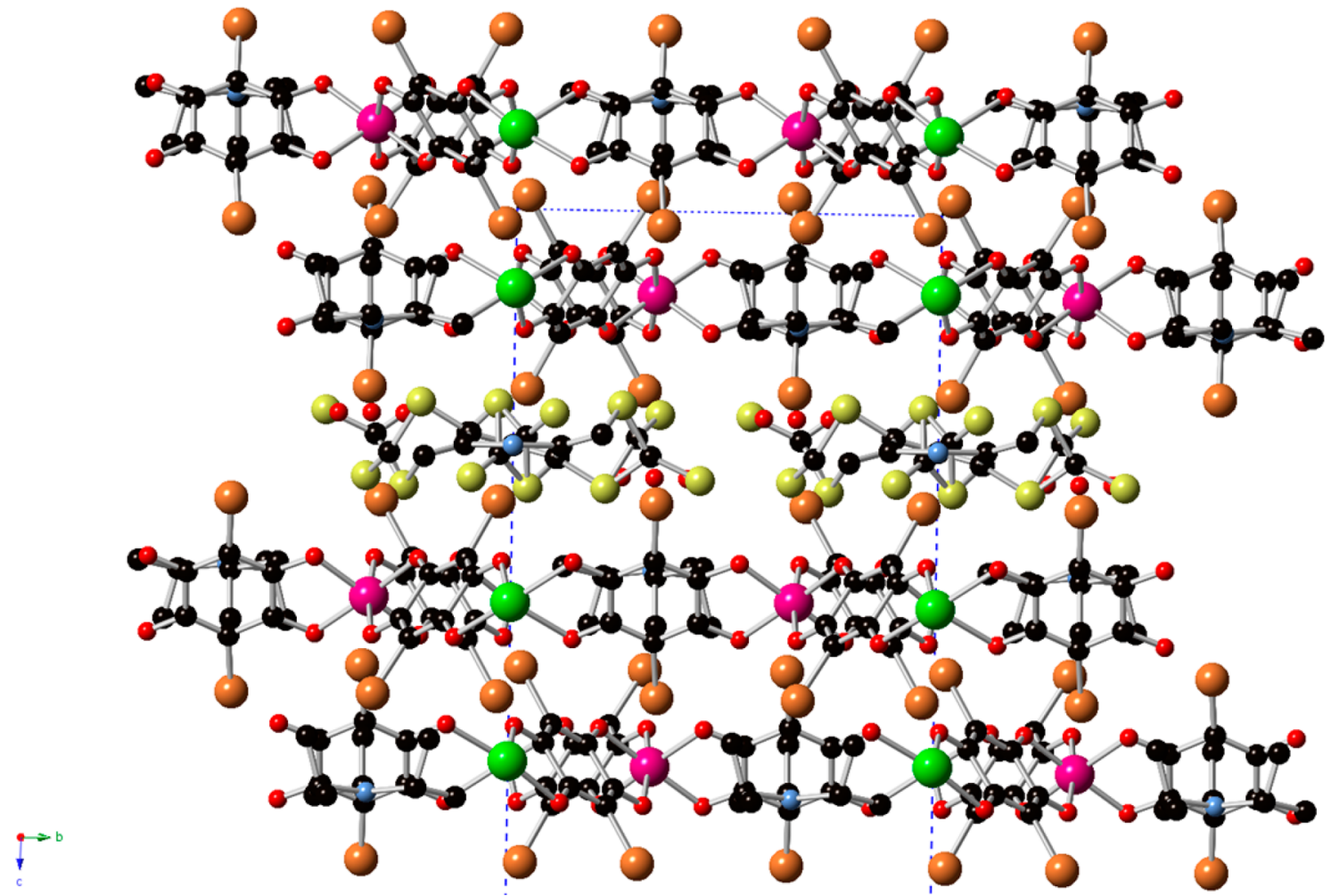

Figure 4. Projection in the $b c$ plane of the compound $\left[(\mathrm{Et})(\mathrm{i}-\mathrm{Pr})_{2} \mathrm{NH}\right]\left[\mathrm{Mn}^{\mathrm{II}} \mathrm{Cr}^{\mathrm{III}}\left(\mathrm{Br}_{2} \mathrm{An}\right)_{3}\right] \cdot\left(\mathrm{CHCl}_{3}\right)_{0.5} \cdot\left(\mathrm{H}_{2} \mathrm{O}\right)$ (4). (Cr (green), Mn (pink) C (black), $\mathrm{N}$ (blue), $\mathrm{O}$ (red), $\mathrm{Cl}$ (yellow), Br (brown)).

problems in the structural resolution (see Experimental Section).

PXRD patterns of freshly filtered crystals of 4 at $300 \mathrm{~K}$ shows some differences with respect to the one calculated from the single crystal X-ray diffraction data, which indicate a very fast loss of solvent molecules (Figure S6). However, the main peaks from the simulated pattern are still observed coexisting with those of a second phase. This pattern changes drastically if it is measured after several days with a clear loss of crystallinity (Figure S6). Interestingly, the change is not irreversible and the original PXRD pattern is partially recovered after soaking the crystals several days in a $\mathrm{CHCl}_{3} / \mathrm{CH}_{3} \mathrm{OH}$ mixture and measuring them with a kapton tape to avoid the loss of solvent molecules. This indicates that the disordered solvent molecules of the interlayer space can be lost and recovered in a reversible way. A similar "breathing" behavior has been observed in the $2 \mathrm{D}$ homometallic anilate-based compound $\left(\mathrm{Me}_{2} \mathrm{NH}_{2}\right)_{2}\left[\mathrm{Fe}_{2} \mathrm{~L}_{3}\right]$. $2 \mathrm{H}_{2} \mathrm{O} \cdot 6 \mathrm{DMF}$ mentioned above and other MOFs. ${ }^{16}$ Finally, the crystallinity of the dry crystals of 4 could be improved by heating at $80{ }^{\circ} \mathrm{C}$ probably thanks to complete desolvation (see Figure S6). On the other hand, PXRD patterns of the precipitate obtained by mixing quickly $\mathrm{MnCl}_{2}$ and $[(\mathrm{Et})(\mathrm{i}-$ $\left.\mathrm{Pr})_{2} \mathrm{NH}\right]_{3}\left[\mathrm{Cr}^{\mathrm{III}}\left(\mathrm{Br}_{2} \mathrm{An}\right)_{3}\right]$ precursors in methanol is very close to that of the desolvated crystals (see Figure S6). This indicates that the slow diffusion in $\mathrm{CHCl}_{3} / \mathrm{MeOH}$ mixtures of these precursors used in the synthesis of $\mathbf{4}$ favors the formation of a structure formed by bilayers, which collapses after losing the solvent molecules in a different one and is similar to that obtained by mixing quickly the precursors. Interestingly, the two structures can be interconverted in a reversible way.

Magnetic Properties. The product of the molar magnetic susceptibility times the temperature $\left(\chi_{\mathrm{M}} \mathrm{T}\right)$ of $\mathbf{1}, \mathbf{2}$, and 3 is shown in Figure 5. It presents at $300 \mathrm{~K}$ values of $7.0 \mathrm{~cm}^{3} \mathrm{~K}$

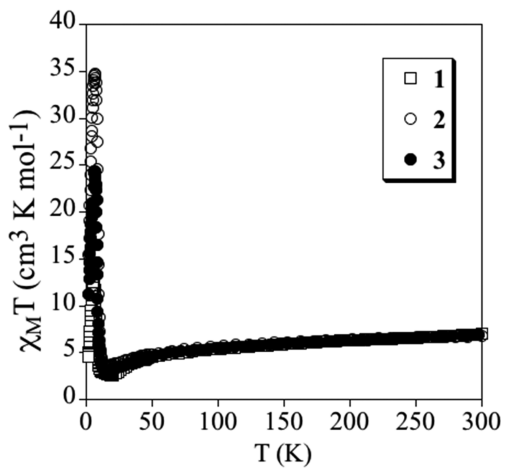

Figure 5. Temperature dependence of the product of the molar magnetic susceptibility times the temperature $\left(\chi_{\mathrm{M}} T\right)$ of $\mathbf{1}$ (empty squares), 2 (empty circles), and 3 (full circles).

$\mathrm{mol}^{-1}$ for $1,6.7 \mathrm{~cm}^{3} \mathrm{~K} \mathrm{~mol}^{-1}$ for 2, and $6.9 \mathrm{~cm}^{3} \mathrm{~K} \mathrm{~mol}^{-1}$ for 3, which are close to the expected value for noninteracting $\mathrm{Mn}$ (II) and $\mathrm{Cr}$ (III) (spin only value of $6.3 \mathrm{~cm}^{3} \mathrm{~K} \mathrm{~mol}^{-1}$ ). When the temperature is lowered, $\chi_{\mathrm{M}} \mathrm{T}$ of the three compounds shows a continuous decrease reaching minima of $2.6 \mathrm{~cm}^{3} \mathrm{~K} \mathrm{~mol}^{-1}$ at 19 $\mathrm{K}$ for $1,3.6 \mathrm{~cm}^{3} \mathrm{~K} \mathrm{~mol}^{-1}$ at $16 \mathrm{~K}$ for 2 , and $3.1 \mathrm{~cm}^{3} \mathrm{~K} \mathrm{~mol}^{-1}$ at $16 \mathrm{~K}$ for 3 followed by a sharp increase at lower temperatures with maxima at ca. $5.6 \mathrm{~K}$ for $1,6.4 \mathrm{~K}$ for 2 , and $6.3 \mathrm{~K}$ for 3 . The decrease of $\chi_{\mathrm{M}} \mathrm{T}$ with the temperature may be attributed to antiferromagnetic $\mathrm{Mn}-\mathrm{Cr}$ interactions mediated through the $\mathrm{X}_{2} \mathrm{An}^{2-}$ bridges, as observed in other compounds containing similar $\left[\mathrm{Mn}^{\mathrm{II}} \mathrm{Cr}{ }^{\mathrm{III}}\left(\mathrm{X}_{2} \mathrm{An}\right)_{3}\right]^{-}$layers. ${ }^{12-14}$ Since the ground spin states of $\mathrm{Cr}(\mathrm{III})$ and $\mathrm{Mn}$ (II) are different $(3 / 2$ and $5 / 2$, respectively), this interaction leads to an antiferromagnetic coupling that results in a $\chi_{\mathrm{m}} \mathrm{T}$ minimum, followed by an increase of $\chi_{\mathrm{m}} \mathrm{T}$ below ca. $20 \mathrm{~K}$, and finally by a ferrimagnetic 
long-range ordering at low temperatures for the three compounds.

The confirmation of the long-range order and a more accurate determination of the ordering temperatures are obtained from the susceptibility measurements performed with an alternating magnetic field (AC susceptibility). These measurements show a frequency-independent peak in the in phase molar susceptibility $\left(\chi_{M}^{\prime}\right)$ and out of phase molar susceptibility $\left(\chi^{\prime \prime}{ }_{M}\right)$ for 1 and 3 (Figure 6). In 2 a secondary
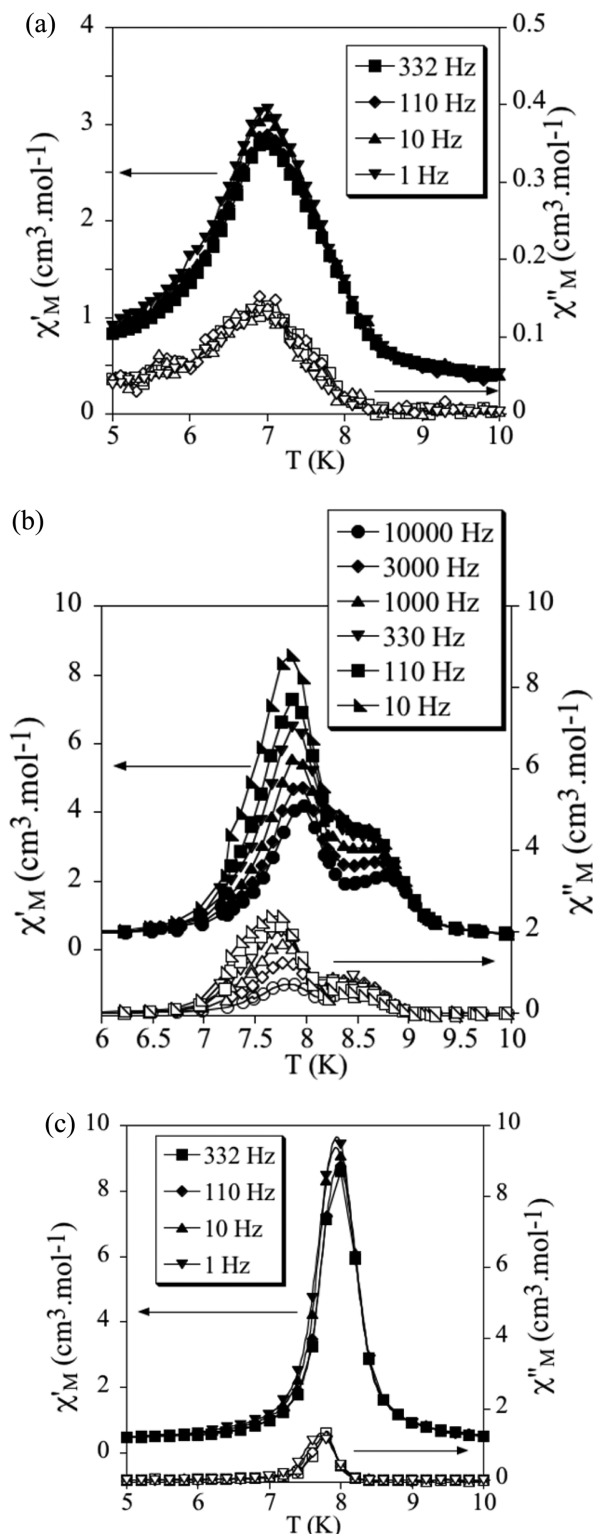

Figure 6. Temperature dependence of the in-phase AC susceptibility $\left(\chi^{\prime}\right)$ (filled symbols) and the out-of-phase AC susceptibility $\left(\chi^{\prime \prime}\right)$ of $\mathbf{1}$ (a), 2 (b), and 3 (c).

peak appears at higher temperatures, which could be related to the presence of some impurity of a solvated phase as suggested by elemental analysis (see above). The $T_{\mathcal{c}}$ determined as the temperature at which $\chi^{\prime \prime}{ }_{\mathrm{M}}$ becomes nonzero, is $7.9 \mathrm{~K}$ for $1,8.9$ $\mathrm{K}$ for 2 and $8.0 \mathrm{~K}$ for 3 . These $T_{\mathrm{c}}$ values are close to those found for $\left[\mathrm{Mn}^{\mathrm{II}} \mathrm{Cr}^{\mathrm{III}}\left(\mathrm{Cl}_{2} \mathrm{An}\right)_{3}\right]^{-}$or $\left[\mathrm{Mn}^{\mathrm{II}} \mathrm{Cr}^{\mathrm{III}}\left(\mathrm{Br}_{2} \mathrm{An}\right)_{3}\right]^{-}$salts of $\left[\mathrm{Fe}^{\mathrm{III}}\left(\mathrm{acac}_{2} \text {-trien }\right)\right]^{+}$and $\left[\mathrm{Fe}^{\mathrm{III}}\left(\mathrm{sal}_{2} \text {-trien }\right)\right]^{+13,1}$
The ferrimagnetic nature of the long-range ordering is confirmed by the isothermal magnetization measurements at 2 $\mathrm{K}$ that show a sharp increase of the magnetization at low fields that becomes more gradual at higher fields (Figure 7). At low
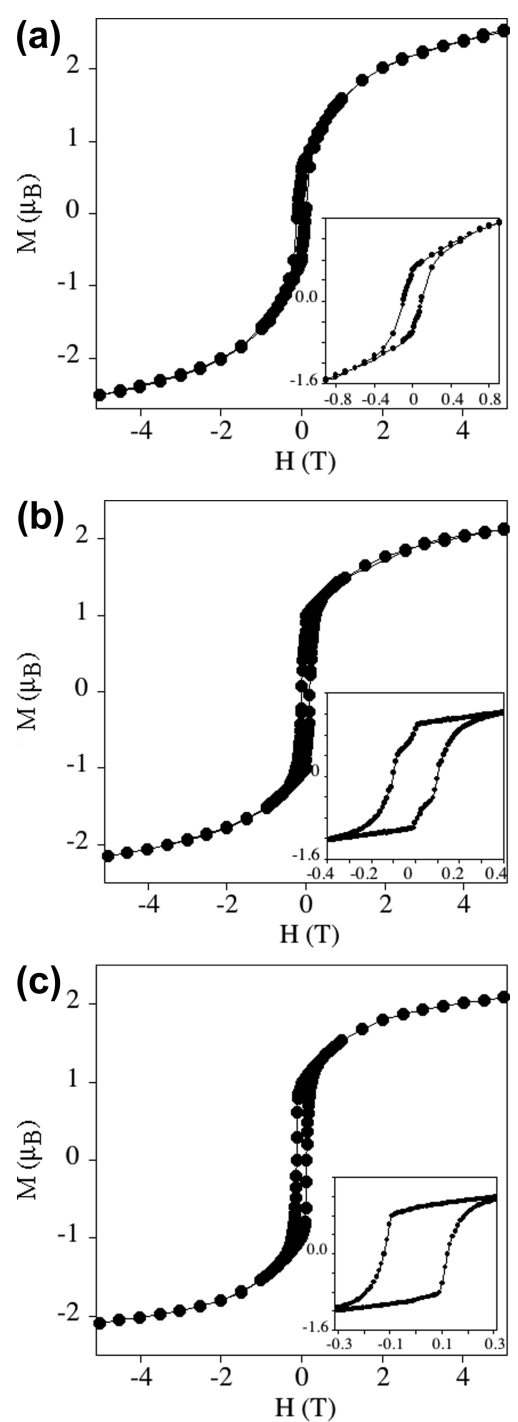

Figure 7. Hysteresis measurements of 1 (a), 2 (b), and 3 (c) at $2 \mathrm{~K}$.

fields $(\mathrm{H}<0.3 \mathrm{~T})$, the magnetization of the three compounds increases with a high slope reaching values of $0.9 \mu \mathrm{B}(1), 1.1 \mu \mathrm{B}$ (2) and $1.1 \mu \mathrm{B}(3)$ at $\mathrm{H}=0.3 \mathrm{~T}$ (insets in Figure 7). At higher fields, the magnetization of $\mathbf{1}, \mathbf{2}$ and 3 tends to saturation (2.5 $\mu \mathrm{B}(1), 2.1 \mu \mathrm{B}(2)$, and $2.2 \mu \mathrm{B}(3)$ at $5 \mathrm{~T})$. These values are close to that expected for a ferrimagnetic $\mathrm{Mn}^{\mathrm{II}} \mathrm{Cr}^{\mathrm{III}}$ network ( $\mathrm{Ms}=5 \mu \mathrm{B}-3 \mu \mathrm{B}=2 \mu \mathrm{B})$. These isothermal magnetization measurements also indicate that these compounds are soft ferrimagnets since they present hysteresis below the ordering temperatures with coercive fields of ca. $90 \mathrm{mT}$ for $1,100 \mathrm{mT}$ for 2 and $150 \mathrm{mT}$ for 3 (insets in Figure 7).

Due to the loss of crystallinity of $\mathbf{4}$ after extracting the crystals from the mother liquor (see above), the magnetic properties of this compound were measured in contact with the solvent $\left(\mathrm{CHCl}_{3} / \mathrm{MeOH}\right.$ mixture $)$. The thermal dependence of $\chi_{\mathrm{M}} \mathrm{T}$ of solvated crystals of 4 is shown in Figure 8. It presents at $300 \mathrm{~K}$ a value of $6.5 \mathrm{~cm}^{3} \mathrm{~K} \mathrm{~mol}{ }^{-1}$, as expected for noninteracting $\mathrm{Mn}$ (II) and $\mathrm{Cr}(\mathrm{III})$. When the temperature is 


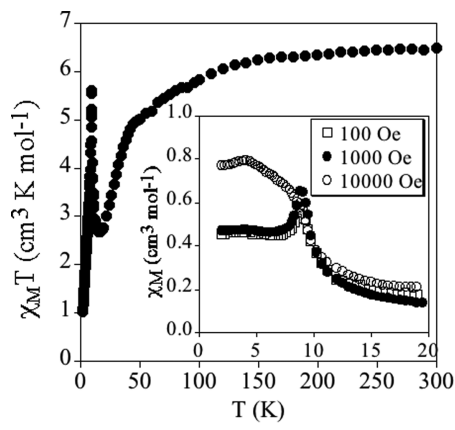

Figure 8. Temperature dependence of the product of the molar magnetic susceptibility times the temperature $\left(\chi_{\mathrm{M}} T\right)$ of crystals of 4 in contact with the mother liquor under an applied dc field of 1000 Oe. The inset shows the temperature dependence of $\chi_{\mathrm{M}}$ under an applied dc field of 100 Oe (empty squares), 1000 Oe (full circles), and 10000 Oe (empty circles).

lowered, $\chi_{\mathrm{M}} \mathrm{T}$ shows a continuous decrease to a minimum of $2.7 \mathrm{~cm}^{3} \mathrm{~K} \mathrm{~mol}^{-1}$ at $15.8 \mathrm{~K}$ close to that of 1,2 , and 3 . The major differences of $\chi_{\mathrm{M}} \mathrm{T}$ of 4 with respect to the other compounds were observed at lower temperatures. Thus, $\chi_{\mathrm{M}} \mathrm{T}$ value increases to a maximum of $5.6 \mathrm{~cm}^{3} \mathrm{~K} \mathrm{~mol}^{-1}$ at $8.9 \mathrm{~K}$, and then decreases to $1.0 \mathrm{~cm}^{3} \mathrm{~K} \mathrm{~mol}^{-1}$ at $2 \mathrm{~K}$. This result indicates that, in contrast to 1,2 , and 3 , compound 4 does not present a ferrimagnetic long-range ordering. The inset of Figure 8 shows the thermal dependence of $\chi_{\mathrm{M}}$ measured under different external dc fields in the temperature range of $2-20 \mathrm{~K}$. A sharp peak is observed at ca. $9 \mathrm{~K}$ at 100 and $1000 \mathrm{Oe}$, which disappears when the external field is 10000 Oe. This could indicate the presence of weak antiferrimagnetic interactions between the ferrimagnetic layers that can be overcome by a high field. These features are characteristic of a metamagnetic behavior, which is confirmed by the sigmoidal shape of the isothermal magnetization at $2 \mathrm{~K}$ (Figure 9). The magnetization

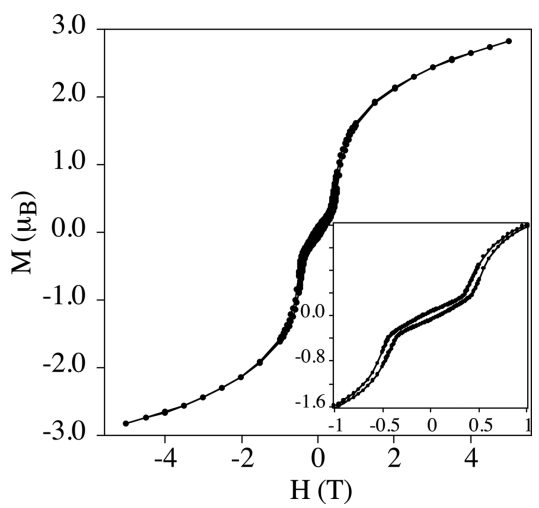

Figure 9. Hysteresis measurements of crystals of 4 at $2 \mathrm{~K}$ measured in contact with the mother liquor.

curve shows a gradual and linear increase at low fields reaching $0.3 \mu \mathrm{B}$ at $\mathrm{H}=0.4 \mathrm{~T}$. This increase becomes very sharp from 0.4 to $1 \mathrm{~T}(\mathrm{M}=1.6 \mu \mathrm{B}$ at $\mathrm{H}=1 \mathrm{~T})$ and increases more gradually at higher magnetic fields without reaching saturation $(\mathrm{M}=2.8 \mu \mathrm{B}$ at $\mathrm{H}=5 \mathrm{~T}$, see Figure 7). The critical field is approximately $\mathrm{H}_{c}$ $=4900$ Oe for this metamagnetic transition determined by the maximum in the $\mathrm{dM} / \mathrm{dH}$ vs $\mathrm{H}$ curve. Small hystereses are observed below and above the $\mathrm{H}_{\mathrm{c}}$ with a coercive field of 80 $\mathrm{mT}$ (see inset of Figure 9). The ac susceptibility measurements (Figure S7) show a frequency-independent peak in $\chi^{\prime}$ at $9.6 \mathrm{~K}$, whereas no out-of-phase signal is observed. All the above magnetic properties are consistent with a field-induced transition from an antiferromagnet to a canted spin structure showing spontaneous magnetization.

The origin of this behavior may be related to the presence of two very different interlayer distances. This novel feature is not observed in compounds containing analogous anilate-based networks, which shows interlayer distances close to the intrabilayer ones of $4(\sim 4.42 \AA$ as in 1,2 , and 3$)$, or close to the interbilayer ones $(\sim 8.76 \AA) \quad\left(\left[\mathrm{Fe}^{\mathrm{III}}\left(\mathrm{acac}_{2}\right.\right.\right.$-trien $\left.)\right]$ $\left[\mathrm{Mn}^{\mathrm{II}} \mathrm{Cr}^{\mathrm{III}}\left(\mathrm{Br}_{2} \mathrm{An}\right)_{3}\right] \cdot\left(\mathrm{CH}_{3} \mathrm{CN}\right)_{2}(7.53 \AA),\left[\mathrm{Ga}^{\mathrm{III}}\left(\mathrm{acac}_{2}\right.\right.$-trien $\left.)\right]$ $\left.\left[\mathrm{Mn}^{\mathrm{II}} \mathrm{Cr}^{\mathrm{III}}\left(\mathrm{Br}_{2} \mathrm{An}\right)_{3}\right] \cdot\left(\mathrm{CH}_{3} \mathrm{CN}\right)_{2}\left(\begin{array}{ll}7.57 & \AA\end{array}\right)\right)^{14}$ The $\mathrm{Br} \cdots \mathrm{Br}$ interbilayer interactions mentioned above, which are not observed between the anilate-based layers of 1,2 , or 3 , could be responsible of the weak antiferromagnetic interaction among the ferrimagnetic layers. On the other hand, intrabilayer interactions seems to be ferromagnetic as in $\mathbf{1}, \mathbf{2}$, or 3 . The synthesis of analogous compounds with $\mathrm{I}_{2} \mathrm{An}$ ligands is in progress to confirm this.

When crystals of $\mathbf{4}$ were extracted from the mother liquor, the magnetic properties change completely and become close to those of 1,2 , and 3. Thus, $\chi_{\mathrm{M}} \mathrm{T}$ of filtered crystals of 4 shows a continuous decrease from $6.9 \mathrm{~cm}^{3} \mathrm{~K} \mathrm{~mol}^{-1}$ at $300 \mathrm{~K}$ to a minimum of $3.0 \mathrm{~cm}^{3} \mathrm{~K} \mathrm{~mol}^{-1}$ at $18 \mathrm{~K}$ followed by a sharp increase at lower temperatures with maxima at ca. $6.9 \mathrm{~K}$ and a very high $\chi_{\mathrm{M}} \mathrm{T}$ value suggesting a ferrimagnetic long-range ordering as that observed in $\mathbf{1}, \mathbf{2}$, and $\mathbf{3}$ (see Figure S8). Thermal dependence of $\chi_{\mathrm{M}}$ of the dry crystals of $\mathbf{4}$ under an applied magnetic field of $0.1 \mathrm{~T}$ confirms this behavior as it shows a sharp increase of $\chi_{\mathrm{M}}$ at decreasing temperatures with much higher values than those of the solvated sample (Figure 10). This is further confirmed by AC susceptibility measure-

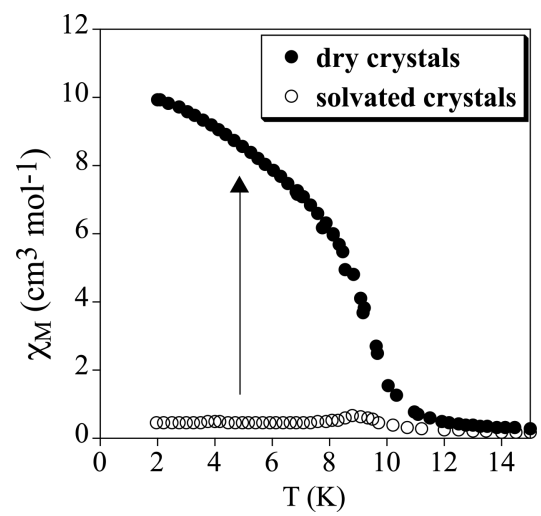

Figure 10. Temperature dependence of the molar magnetic susceptibility times the temperature $\left(\chi_{\mathrm{M}}\right)$ of crystals of $\mathbf{4}$ in contact with the mother liquor (empty circles) or after filtering (full circles) under an applied dc field of 1000 Oe.

ments, which show a frequency-independent peak in $\chi_{{ }_{M}}^{\prime}$ and $\chi^{\prime \prime}{ }_{\mathrm{M}}$ with a $T_{\mathrm{c}}$ of $9.0 \mathrm{~K}$ (see Figure S9), and the isothermal magnetization at $2 \mathrm{~K}$. Thus, $\mathrm{M}$ of dried crystals of 4 shows a sharp increase at low fields that becomes more gradual at higher fields reaching $2.0 \mu \mathrm{B}$ at $5 \mathrm{~T}$ (see Figure S10). It presents a hysteresis loop with a coercive field of ca. $4 \mathrm{mT}$ (inset in Figure S10). The shape of the hysteresis loop of the dried crystals of 4 is different to that of $\mathbf{1}, \mathbf{2}$, and $\mathbf{3}$ and other compounds with similar anilate-based networks. Thus, it presents a much more abrupt increase of $\mathrm{M}$ at low magnetic fields and the presence of steps. A possible explanation of the absence of metamagnetism 
in the desolvated crystals is the collapse of the structure after extracting the crystals from the mother liquor suggested by powder X-ray diffraction data (see above and Figure S6), which could lead to different interlayer magnetic interactions in the absence of $\mathrm{Br} \cdots \mathrm{Br}$ interlayer interactions. Interestingly, this behavior is reversible in agreement with $\mathrm{X}$-ray powder diffraction data that suggest that the original structure is recovered after reimmersing the crystals in a $\mathrm{CHCl}_{3} / \mathrm{MeOH}$ mixture. AC susceptibility measurements of the same crystals reimmersed in a $\mathrm{CHCl}_{3} / \mathrm{MeOH}$ mixture overnight and measured in contact with this solvent mixture (resolvated sample) do not show the peak in $\chi^{\prime \prime}{ }_{M}$ observed in the dry sample (Figure S11). On the other hand, the maximum in $\chi^{\prime}{ }_{M}$ at $9 \mathrm{~K}$, of the solvated sample is observed in the resolvated sample with similar values. Therefore, the metamagnetic behavior of a solvated sample of $\mathbf{4}$ is recovered. We thus observe a reversible switching of the magnetic properties, which resembles that observed in the $2 \mathrm{D}$ homometallic anilate-based compound $\left(\mathrm{Me}_{2} \mathrm{NH}_{2}\right)_{2}\left[\mathrm{Fe}_{2}\left(\mathrm{~L}_{1}\right)_{3}\right] \cdot 2 \mathrm{H}_{2} \mathrm{O} \cdot 6 \mathrm{DMF}$ mentioned above $^{16}$ that shows a reversible decrease of the magnetic ordering temperature after desolvation from 80 to $26 \mathrm{~K}$. Still, this solvent-induced magnetic switching has a different origin to that of 4 . This is attributed to the distortion of the framework and/or the creation of defects upon desolvation, as the absence of an inflection point in $\mathrm{M}$ vs $\mathrm{H}$ curves suggests that the interlayer interaction is negligible or ferromagnetic. ${ }^{16}$ In fact, halogen-halogen interactions are not observed in this homometallic compound.

Thermal Analysis and Proton Conductivity. Compounds 2, 3, and 4 show similar thermal behavior with a small weight loss between room temperature and $50{ }^{\circ} \mathrm{C}$, which is due, likely, to the removal of an amount of physisorbed water/solvent by the solids. After this temperature, compounds remain thermally stable up to $\sim 240-260{ }^{\circ} \mathrm{C}$, temperature at which decomposition of the solids take place (data not shown). In 1, a higher weight loss was observed below $140{ }^{\circ} \mathrm{C}(3.5 \%)$, which is consistent with the presence of two water molecules in the polycrystalline sample (Figure S12). After proton conductivity measurements, pelletized samples were analyzed by TGA and PXRD, in order to notice possible structural and/ or water content changes. None of the solids displayed significant weight gain or changes in their PXRD patterns (Figure S13), underlining the stability of the samples in the full range of temperature $\left(25\right.$ to $\left.70{ }^{\circ} \mathrm{C}\right)$ and relative humidity $(95 \%$ $\mathrm{RH})$ analyzed. Impedance spectra registered under these conditions are shown in Figure S14. The total pellet resistance, $\mathrm{R}_{\mathrm{T}}$, was obtained from the intercept of the spike and/or the arc (low- frequency end) on the $\mathrm{Z}^{\prime}$ axis. The highest proton conductivity values, at $70{ }^{\circ} \mathrm{C}$ and $95 \% \mathrm{RH}$, are obtained for compounds $1\left(2.4 \times 10^{-5} \mathrm{~S} \cdot \mathrm{cm}^{-1}\right)$ and $4\left(1 \times 10^{-5} \mathrm{~S} \cdot \mathrm{cm}^{-1}\right)$ and the lowest for 2 and 3 , with proton conductivities close to 2 $\times 10^{-6} \mathrm{~S} \cdot \mathrm{cm}^{-1}$. The weak H-bond network formed between the protonated nitrogen atoms of the intercalated alkylammonium cations with the oxygen and halogen atoms of the anilate groups, with interaction distances $\mathrm{N} \cdots \mathrm{O}$ and $\mathrm{N} \cdots \mathrm{X}(\mathrm{X}=\mathrm{Cl}, \mathrm{Br})$ longer than $3.4 \AA$, makes difficult the proton transfers and leads to low proton conductivity values. The low activation energy values, range between $0.26 \mathrm{eV}$ (for 1, 2 and 4) and $0.15 \mathrm{eV}$ (3) obtained from the Arrhenius plot, Figure 11, are consistent with a Grotthuss $\mathrm{H}^{+}$transfer mechanism, ${ }^{28}$ although a vehicle mechanism contribution cannot be discarded. ${ }^{29}$ These results confirm the existence of proton conductivity without reaching the best results for oxalate-based systems $\left(\sigma \sim 10^{-3}{\mathrm{~S} . \mathrm{cm}^{-1}}^{10}{ }^{10}\right.$

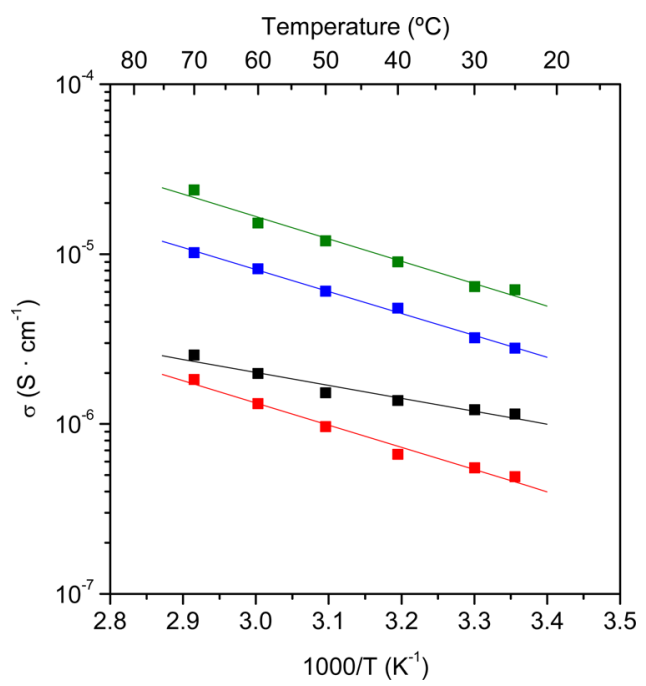

Figure 11. Arrhenius plot at 95\% RH for compounds 1 (green), 2 (red), 3 (black), and 4 (blue)).

On the other hand, these values are similar to those found on coordination polymers based on similar ligands with a $1 \mathrm{D}$ structure in compounds $\mathrm{M}^{\mathrm{II}}(\mathrm{dhbq}) \cdot \mathrm{nH}_{2} \mathrm{O}(\mathrm{M}=\mathrm{Mg}, \mathrm{Mn}, \mathrm{Co}$, $\mathrm{Ni}$, and $\mathrm{Zn}$ ), which have shown $\sigma$ values of $10^{-4} \mathrm{~S} . \mathrm{cm}^{-1}$ when noncoordinating crystalline water is absorbed into the voids of the $1 \mathrm{D}$ array with humidity. ${ }^{30}$

\section{CONCLUSIONS}

Four novel magnetic compounds formed by $\mathrm{Me}_{2} \mathrm{NH}_{2}{ }^{+}$, $\mathrm{Et}_{2} \mathrm{NH}_{2}{ }^{+}, \mathrm{Et}_{3} \mathrm{NH}^{+}$, and $\left[(\mathrm{Et})(\mathrm{i}-\mathrm{Pr})_{2} \mathrm{NH}\right]^{+}$and anionic bimetallic coordination polymers based on the anilate ligand have been prepared and characterized. They contain 2D anilate-based networks with a honeycomb structure. The compounds containing the smaller templating cations $\mathrm{Me}_{2} \mathrm{NH}_{2}{ }^{+}, \mathrm{Et}_{2} \mathrm{NH}_{2}{ }^{+}$, and $\mathrm{Et}_{3} \mathrm{NH}^{+}(1,2$, and 3) present structures, in which the cations are placed into the hexagonal channels of the 2D network as observed previously with $\left[\mathrm{Fe}^{\mathrm{III}}\left(\mathrm{acac}_{2} \text {-trien }\right)\right]^{+}$. Interestingly, a relatively small increase in the size of the templating cation $\left(\left[(\mathrm{Et})(\mathrm{i}-\mathrm{Pr})_{2} \mathrm{NH}\right]^{+}\right)$, gives rise in 4 to a different structure with half of the cations placed within the layers and the other half between them leading to bilayers separated by a layer of disordered solvent molecules and countercations. These structural differences lead to abrupt changes in the magnetism of these lattices. Compounds 1, 2, and 3 present a ferrimagnetic ordering with a $T_{c}$ similar to that of other $2 \mathrm{D}$ anilate-based compounds with the same metals, while in 4 , the presence of weak magnetic interactions between the ferrimagnetic layers, which could be mediated by halogenhalogen interactions, gives rise to a metamagnetic behavior when the sample is measured in contact with the mother liquor. The behavior changes in the desolvated sample, which shows a ferrimagnetic ordering as that of 1,2 , and 3 due to collapse of the structure. Interestingly, the metamagnetic behavior is recovered after reimmersing the crystals in the mother liquor proving the reversibility of the process, which is confirmed by powder X-ray diffraction.

Proton conductivity measurements for the four compounds show values comparable to those of bimetallic oxalate-based compounds containing acidic cations without reaching the best values of these systems. One reason for the lower conductivity could be the alternated configuration of the anilate layers, which prevents close contacts between the alkylammonium 
cations. These results indicate that anilate-based compounds are promising candidates for the preparation of multifunctional compounds with coexistence of magnetic ordering and proton conduction. The interplay between both properties could be reached in compounds with higher magnetic ordering temperature and proton conduction. Possible strategies to improve the proton conduction are the enhancement of the interlayer and intralayer transport trough the proton carriers. This could be achieved with an eclipsed disposition of the layers to favor the interlayer transport and increasing the number of proton carriers to favor the intralayer transport. Homometallic anilatebased compounds reported in the literature such as $\left(\left(\mathrm{Me}_{2} \mathrm{NH}_{2}\right)_{2}\left[\mathrm{Fe}_{2}\left(\mathrm{~L}_{1}\right)_{3}\right] \cdot 2 \mathrm{H}_{2} \mathrm{O} \cdot 6 \mathrm{DMF}\right.$ containing partially reduced anilate ligands fulfill these two requisites together with porosity and electric conductivity. ${ }^{16}$ However, the proton conduction of these compounds could be limited due to stability problems as they are prepared and studied in an inert atmosphere.

Possible advantages of the heterometallic compounds prepared in this work are the neutral character of the anilatebased layers due to the presence of the countercations into the hexagonal channels of the 2D network of the structure. This opens interesting perspectives for the exfoliation of single magnetic layers of these compounds as it has been done with $\left[\mathrm{Fe}^{\mathrm{III}}\left(\mathrm{acac}_{2} \text {-trien }\right)\right]^{+}$anilate-based compounds. On the other hand, the reversible solvent-induced change of the structure and magnetic properties of $\mathbf{4}$ could be extended to other solvents or neutral molecules for sensing or for the preparation of multifunctional compounds. To reach this goal, we are currently exploring the intercalation chemistry of this compound and related ones.

\section{ASSOCIATED CONTENT}

\section{(S Supporting Information}

The Supporting Information is available free of charge on the ACS Publications website at DOI: 10.1021/acs.inorgchem.7b01965.

Structural views of the structures, powder X-ray diffraction patterns of the compounds, magnetic measurements of 4, TGA of 1 , and complex impedance plane plots of the compounds (PDF)

\section{Accession Codes}

CCDC 1491090-1491091 and 1564529-1564530 contain the supplementary crystallographic data for this paper. These data can be obtained free of charge via www.ccdc.cam.ac.uk/ data_request/cif, or by emailing data_request@ccdc.cam.ac. uk, or by contacting The Cambridge Crystallographic Data Centre, 12 Union Road, Cambridge CB2 1EZ, UK; fax: +44 1223336033.

\section{AUTHOR INFORMATION}

\section{Corresponding Authors}

*Tel: (+34) 96 3544415. Fax: (+34) 96354 3273. E-mail: miguel.clemente@uv.es.

*E-mail: eugenio.Coronado@uv.es.

\section{ORCID}

Enrique R. Losilla: 0000-0002-3361-2340

Aurelio Cabeza: 0000-0002-1582-3240

Miguel Clemente-León: 0000-0003-3868-1078

Notes

The authors declare no competing financial interest.

\section{ACKNOWLEDGMENTS}

Financial support from the EU (ERC Advanced Grant SPINMOL), the Spanish MINECO (CTQ2014-52758-P grant, MAT-2014-56143-R and Unidad de Excelencia Maria de Maeztu MDM-2015-0538), the Generalitat Valenciana (Prometeo) is gratefully acknowledged. The work at UMA was funded by Spanish MINECO through MAT2016-77648-R, which is cofunded by FEDER and by Junta de Andalucia through P12-FQM-1656 research projects. We thank J. M. Martinez-Agudo and G. Agusti from the Universidad de Valencia for the magnetic measurements. Gabriel Peris-Pérez from Universitat Jaume I is gratefully acknowledged for single crystal X-ray diffraction measurements of 3 .

\section{REFERENCES}

(1) (a) Coronado, E.; Day, P. Magnetic molecular conductors. Chem. Rev. 2004, 104, 5419-5448. (b) Coronado, E.; Martí-Gastaldo, C.; Navarro-Moratalla, E.; Ribera, A.; Blundell, S. J.; Baker, P. J. Coexistence of superconductivity and magnetism by chemical design. Nat. Chem. 2010, 2, 1031-1036. (c) Coronado, E.; Martí-Gastaldo, C.; Navarro-Moratalla, E.; Burzuri, E.; Camon, E.; Luis, F. Hybrid Magnetic/Superconducting Materials Obtained by Insertion of a Single-Molecule Magnet into $\mathrm{TaS}_{2}$ Layers. Adv. Mater. 2011, 23, 5021-5026. (d) Abellán, G.; Martí-Gastaldo, C.; Ribera, A.; Coronado, E. Hybrid Materials Based on Magnetic Layered Double Hydroxides: A Molecular Perspective. Acc. Chem. Res. 2015, 48, 16011611.

(2) Clemente-León, M.; Coronado, E.; Martí-Gastaldo, C.; Romero, F. M. Multifunctionality in hybrid magnetic materials based on bimetallic oxalate complexes. Chem. Soc. Rev. 2011, 40, 473-497.

(3) (a) Clemente-León, M.; Coronado, E.; Galán-Mascarós, J. R.; Gómez-García, C. J. Intercalation of decamethylferrocenium cations in bimetallic oxalate-bridged two-dimensional magnets. Chem. Commun. 1997, 1727-1728. (b) Coronado, E.; Galán-Mascarós, J. R.; GómezGarcía, C. J.; Martínez-Agudo, J. M. Increasing the Coercivity in Layered Molecular-based Magnets A $\left[\mathrm{M}^{\mathrm{II}} \mathrm{M}^{\mathrm{III}}(\mathrm{ox})_{3}\right]\left(\mathrm{M}^{\mathrm{II}}=\mathrm{Mn}, \mathrm{Fe}, \mathrm{Co}\right.$, $\mathrm{Ni}, \mathrm{Cu} ; \mathrm{M}^{\mathrm{III}}=\mathrm{Cr}, \mathrm{Fe}$; ox = oxalate; $\mathrm{A}=$ organic or organometallic cation). Adv. Mater. 1999, 11, 558-561. (c) Coronado, E.; GalánMascarós, J. R.; Gómez-García, C. J.; Ensling, J.; Gutlich, P. Hybrid Molecular Magnets Obtained by Insertion of Decamethylmetallocenium Cations into Layered, Bimetallic Oxalate Complexes: [ $\left.\mathrm{Z}^{\mathrm{III}} \mathrm{Cp}_{2}{ }_{2}\right]$ $\left[\mathrm{M}^{\mathrm{II}} \mathrm{M}^{\mathrm{III}}(\mathrm{ox})_{3}\right]\left(\mathrm{Z}^{\mathrm{III}}=\mathrm{Co}, \mathrm{Fe} ; \mathrm{M}^{\mathrm{III}}=\mathrm{Cr}, \mathrm{Fe} ; \mathrm{MII}=\mathrm{Mn}, \mathrm{Fe}, \mathrm{Co}, \mathrm{Cu}, \mathrm{Zn}\right.$; ox $=$ oxalate; $\mathrm{Cp}^{*}=$ pentamethylcyclopentadienyl). Chem. - Eur. J. 2000, 6, 552-563.

(4) (a) Bénard, S.; Yu, P.; Audière, J. P.; Rivière, E.; Clèment, R.; Guilhem, J.; Tchertanov, L.; Nakatani, K. Structure and NLO Properties of Layered Bimetallic Oxalato-Bridged Ferromagnetic Networks Containing Stilbazolium-Shaped Chromophores. J. Am. Chem. Soc. 2000, 122, 9444-9454. (b) Aldoshin, S. M.; Sanina, N. A.; Minkin, V. I.; Voloshin, N. A.; Ikorskii, V. N.; Ovcharenko, V. I.; Smirnov, V. A.; Nagaeva, N. K. Molecular photochromic ferromagnetic based on the layered polymeric tris-oxalate of $\mathrm{Cr}(\mathrm{III}), \mathrm{Mn}(\mathrm{II})$ and $1-$ $\left[\left(1^{\prime}, 3^{\prime}, 3^{\prime}\right.\right.$-trimethyl-6-nitrospiro[2H-1-benzopyran-2,2' -indoline $]-8$ yl)methyl]pyridinium. J. Mol. Struct. 2007, 826, 69-74.

(5) (a) Coronado, E.; Galán-Mascarós, J. R.; Gómez-García, C. J.; Laukhin, V. Coexistence of ferromagnetism and metallic conductivity in a molecule-based layered compound. Nature 2000, 408, 447-449. (b) Alberola, A.; Coronado, E.; Galán-Mascarós, J. R.; Giménez-Saiz, C.; Gómez-García, C. J. A Molecular Metal Ferromagnet from the Organic Donor Bis(ethylenedithio)tetraselenafulvalene and Bimetallic Oxalate Complexes. J. Am. Chem. Soc. 2003, 125, 10774-10775. (c) Galán-Mascarós, J. R.; Coronado, E.; Goddard, P. A.; Singleton, J.; Coldea, A. I.; Wallis, J. D.; Coles, S. J.; Alberola, A. A Chiral Ferromagnetic Molecular Metal. J. Am. Chem. Soc. 2010, 132, 92719273. (d) Coronado, E.; Galán-Mascarós, J. R.; Gómez-García, C. J.; Martínez-Ferrero, E.; Van Smaalen, S. Incommensurate Nature of the Multilayered Molecular Ferromagnetic Metals Based on Bis- 
(ethylenedithio)tetrathiafulvalene and Bimetallic Oxalate Complexes. Inorg. Chem. 2004, 43, 4808-4810. (e) Zhang, B.; Zhang, Y.; Zhu, D. (BEDT-TTF $)_{3} \mathrm{Cu}_{2}\left(\mathrm{C}_{2} \mathrm{O}_{4}\right)_{3}\left(\mathrm{CH}_{3} \mathrm{OH}\right)_{2}$ : an organic-inorganic hybrid antiferromagnetic semiconductor. Chem. Commun. 2012, 48, 197-199.

(6) (a) Endo, T.; Akutagawa, T.; Noro, S. I.; Nakamura, T. Supramolecular cations of the m-fluoroanilinium(dibenzo[18]crown6) in ferromagnetic salt. Dalton Trans. 2011, 40, 1491-1496. (b) Pardo, E.; Train, C.; Liu, H.; Chamoreau, L.-M.; Dkhil, B.; Boubekeur, K.; Lloret, F.; Nakatani, K.; Tokoro, H.; Ohkoshi, S.-i.; Verdaguer, M. Multiferroics by Rational Design: Implementing Ferroelectricity in Molecule-Based Magnets. Angew. Chem., Int. Ed. 2012, 51, 8356-8360.

(7) (a) Andrés, R.; Gruselle, M.; Malézieux, B.; Verdaguer, M.; Vaissermann, J. Inorg. Chem. 1999, 38, 4637-4646. (b) Andrés, R; Brissard, M.; Gruselle, M.; Train, C.; Vaissermann, J.; Malézieux, B.; Jamet, J. P.; Verdaguer, M. Rational Design of Three-Dimensional (3D) Optically Active Molecule-Based Magnets: Synthesis, Structure, Optical and Magnetic Properties of $\left\{\left[\mathrm{Ru}(\text { bpy })_{3}\right]^{2+}, \mathrm{ClO}_{4}^{-}\right.$, $\left.\left[\mathrm{Mn}^{\mathrm{II}} \mathrm{Cr}^{\mathrm{III}}(\mathrm{ox})_{3}\right]^{-}\right\}_{\mathrm{n}}$ and $\left\{\left[\mathrm{Ru}(\mathrm{bpy})_{2} \mathrm{Ppy}\right]^{+}, \quad\left[\mathrm{M}^{\mathrm{II}} \mathrm{Cr}^{\mathrm{III}}(\mathrm{ox})_{3}\right]^{-}\right\}_{\mathrm{n}}$, with $\mathrm{M}^{\mathrm{II}}=\mathrm{Mn}^{\mathrm{II}}, \mathrm{Ni}^{\mathrm{II}}$. X-ray Structure of $\left\{\left[\Delta \mathrm{Ru}(\mathrm{bpy})_{3}\right]^{2+}, \mathrm{ClO}_{4}^{-}\right.$, $\left.\left[\Delta \mathrm{Mn}^{\mathrm{II}} \mathrm{Cr}^{\mathrm{III}}(\text { ox })_{3}\right]^{-}\right\}_{\mathrm{n}}$ and $\left\{\left[\Lambda \mathrm{Ru}(\mathrm{bpy})_{2} \mathrm{ppy}\right]^{+},\left[\Lambda \mathrm{Mn}^{\mathrm{II}} \Lambda \mathrm{Cr}^{\mathrm{III}}(\text { ox })_{3}\right]^{-}\right\}_{\mathrm{n}}$. Inorg. Chem. 2001, 40, 4633-4640. (c) Clemente-León, M.; Coronado, E.; Dias, J. C.; Soriano-Portillo, A.; Willett, R. D. Synthesis, Structure, and Magnetic Properties of $\left[(\mathrm{S})-\left[\mathrm{PhCH}\left(\mathrm{CH}_{3}\right) \mathrm{N}\left(\mathrm{CH}_{3}\right)_{3}\right]\right]$ $\left[\mathrm{Mn}\left(\mathrm{CH}_{3} \mathrm{CN}\right)_{2 / 3} \mathrm{Cr}(\mathrm{ox})_{3}\right] \cdot\left(\mathrm{CH}_{3} \mathrm{CN}\right)_{-}($solvate $)$, a $2 \mathrm{D}$ Chiral Magnet Containing a Quaternary Ammonium Chiral Cation. Inorg. Chem. 2008, 47, 6458-6463. (d) Train, C.; Gheorghe, R.; Krstic, V.; Chamoreau, L. M.; Ovanesyan, N. S.; Rikken, G. L. J. A.; Gruselle, M.; Verdaguer, M. Strong magneto-chiral dichroism in enantiopure chiral ferromagnets. Nat. Mater. 2008, 7, 729-734. (e) Train, C.; Nuida, T.; Gheorghe, R.; Gruselle, M.; Ohkoshi, S. Large Magnetization-Induced Second Harmonic Generation in an Enantiopure Chiral Magnet. J. Am. Chem. Soc. 2009, 131, 16838-16843. (f) Gruselle, M.; Li, Y.; Ovanesyan, N.; Makhaev, V.; Shilov, G.; Mushenok, F.; Train, C.; Aldoshin, S. (S)-(-)-(2-MeBu) $\mathrm{N}(\mathrm{Pr})_{2} \mathrm{MeI}$ Salt as Template in the Enantioselective Synthesis of the Enantiopure Two-dimensional $(S)$ $(-)-(2-\mathrm{MeBu}) \mathrm{N}(\mathrm{Pr})_{2} \mathrm{Me}\left[\Lambda \mathrm{Mn} \Delta \mathrm{Cr}\left(\mathrm{C}_{2} \mathrm{O}_{4}\right)_{3}\right]$ Ferromagnet. Chirality 2013, 25, 444-448.

(8) Clemente-León, M.; Coronado, E.; Gómez-García, C. J.; LópezJordà, M.; Camón, A.; Repollés, A.; Luis, F. Insertion of a SingleMolecule Magnet inside a Ferromagnetic Lattice Based on a 3D Bimetallic Oxalate Network: Towards Molecular Analogues of Permanent Magnets. Chem. - Eur. J. 2014, 20, 1669-1676.

(9) (a) Clemente-León, M.; Coronado, E.; Giménez-López, M. C.; Soriano-Portillo, A.; Waerenborgh, J. C.; Delgado, F. S.; Ruiz-Pérez, C. Insertion of a Spin Crossover Fe ${ }^{\mathrm{III}}$ Complex into an Oxalate-Based Layered Material: Coexistence of Spin Canting and Spin Crossover in a Hybrid Magnet. Inorg. Chem. 2008, 47, 9111-9120. (b) ClementeLeón, M.; Coronado, E.; López-Jordà, M.; Mínguez Espallargas, G.; Soriano-Portillo, A.; Waerenborgh, J. C. Multifunctional Magnetic Materials Obtained by Insertion of a Spin-Crossover Fe ${ }^{\text {III }}$ Complex into Bimetallic Oxalate-Based Ferromagnets. Chem. - Eur. J. 2010, 16, 2207-2219. (c) Clemente-León, M.; Coronado, E.; López-Jordà, M. $2 \mathrm{D}$ and $3 \mathrm{D}$ bimetallic oxalate-based ferromagnets prepared by insertion of different $\mathrm{Fe}^{\mathrm{III}}$ spin crossover complexes. Dalton Trans. 2010, 39, 4903-4910. (d) Clemente-León, M.; Coronado, E.; LópezJordà, M.; Waerenborgh, J. C. Multifunctional Magnetic Materials Obtained by Insertion of Spin-Crossover Fe ${ }^{\text {III }}$ Complexes into Chiral 3D Bimetallic Oxalate-Based Ferromagnets. Inorg. Chem. 2011, 50, 9122-9130. (e) Clemente-León, M.; Coronado, E.; López-Jordà, M.; Desplanches, C.; Asthana, S.; Wang, H.; Létard, J.-F. A hybrid magnet with coexistence of ferromagnetism and photoinduced $\mathrm{Fe}(\mathrm{III})$ spincrossover. Chem. Sci. 2011, 2, 1121-1127. (f) Clemente-León, M.; Coronado, E.; López-Jordà, M. 2D Bimetallic Oxalate-Based Ferromagnets with Inserted $\left[\mathrm{Fe}\left(4-\mathrm{Br}_{-} \mathrm{sal}_{2} \text {-trien }\right)\right]^{+}$and $\left[\mathrm{Fe}\left(3-\mathrm{R}-\mathrm{sal}_{2}{ }_{-}^{-}\right.\right.$ trien $)]^{+}\left(\mathrm{R}=\mathrm{Br}, \mathrm{Cl}\right.$ and $\left.\mathrm{CH}_{3} \mathrm{O}\right) \mathrm{Fe}^{\mathrm{III}}$ Spin-Crossover Complexes. Eur. J. Inorg. Chem. 2013, 2013, 753-762. (g) Ben Djamâa, A.; ClementeLeón, M.; Coronado, E.; López-Jordà, M. Insertion of $\mathrm{Fe}^{\mathrm{II}}$ complexes with Schiff base ligands derived from imidazole or pyridine into 3D bimetallic oxalate-based ferromagnets. Polyhedron 2013, 64, 142-150. (h) Clemente-León, M.; Coronado, E.; López-Jordà, M.; Waerenborgh, J. C.; Desplanches, C.; Wang, H.; Létard, J.-F.; Hauser, A.; Tissot, A. Stimuli Responsive Hybrid Magnets: Tuning the Photoinduced Spin-Crossover in Fe(III) Complexes Inserted into Layered Magnets. J. Am. Chem. Soc. 2013, 135, 8655-8677. (i) LópezJordà, M.; Giménez-Marqués, M.; Desplanches, C.; Mínguez Espallargas, G.; Clemente-León, M.; Coronado, E. Insertion of a $\left[\mathrm{Fe}^{\mathrm{II}}(\text { pyimH })_{3}\right]^{2+}[$ pyimH $=2$ - $(1 \mathrm{H}$-Imidazol-2-yl $)$ pyridine $]$ SpinCrossover Complex Inside a Ferromagnetic Lattice Based on a Chiral 3D Bimetallic Oxalate Network. Eur. J. Inorg. Chem. 2016, 2016, 2187-2192.

(10) (a) Okawa, H.; Shigematsu, A.; Sadakiyo, M.; Miyagawa, T.; Yoneda, K.; Ohba, M.; Kitagawa, H. Oxalate-Bridged Bimetallic Complexes $\left\{\mathrm{NH}(\mathrm{prol})_{3}\right\}\left[\mathrm{MCr}(\mathrm{ox})_{3}\right]\left(\mathrm{M}=\mathrm{Mn}^{\mathrm{II}}, \mathrm{Fe}^{\mathrm{II}}, \mathrm{Co}^{\mathrm{II}} ; \mathrm{NH}-\right.$ $(\text { prol })_{3}{ }^{+}=\operatorname{Tri}(3$-hydroxypropyl)ammonium) Exhibiting Coexistent Ferromagnetism and Proton Conduction. J. Am. Chem. Soc. 2009, 131, 13516-13522. (b) Pardo, E.; Train, C.; Gontard, G.; Boubekeur, K.; Fabelo, O.; Liu, H.; Dkhil, B.; Lloret, F.; Nakagawa, K.; Tokoro, H.; Ohkoshi, S. - I.; Verdaguer, M. High Proton Conduction in a Chiral Ferromagnetic Metal-Organic Quartz-like Framework. J. Am. Chem. Soc. 2011, 133, 15328-15331. (c) Sadakiyo, M.; Okawa, H.; Shigematsu, A.; Ohba, M.; Yamada, T.; Kitagawa, H. Promotion of Low-Humidity Proton Conduction by Controlling Hydrophilicity in Layered Metal-Organic Frameworks. J. Am. Chem. Soc. 2012, 134, 5472-5475. (d) Okawa, H.; Sadakiyo, M.; Yamada, T.; Maesato, M.; Ohba, M.; Kitagawa, H. Proton-Conductive Magnetic Metal-Organic Frameworks, $\left\{\mathrm{NR}_{3}\left(\mathrm{CH}_{2} \mathrm{COOH}\right)\right\}\left[\mathrm{M}_{\mathrm{a}} \mathrm{II}_{\mathrm{b}}{ }^{\mathrm{III}}(\mathrm{ox})_{3}\right]$ : Effect of Carboxyl Residue upon Proton Conduction. J. Am. Chem. Soc. 2013, 135, 22562262. (e) Maxim, C.; Ferlay, S.; Tokoro, H.; Ohkoshi, S. I.; Train, C. Atypical stoichiometry for a 3D bimetallic oxalate-based long-range ordered magnet exhibiting high proton conductivity. Chem. Commun. 2014, 50, 5629-5632. (f) Sadakiyo, M.; Yamada, T.; Honda, K.; Matsui, H.; Kitagawa, H. Control of Crystalline Proton-Conducting Pathways by Water-Induced Transformations of Hydrogen-Bonding Networks in a Metal-Organic Framework. J. Am. Chem. Soc. 2014, 136, 7701-7707. (g) Okawa, H.; Sadakiyo, M.; Otsubo, K.; Yoneda, K.; Yamada, T.; Ohba, M.; Kitagawa, H. Proton Conduction Study on Water Confined in Channel or Layer Networks of $\mathrm{La}^{\mathrm{III}} \mathrm{M}^{\mathrm{III}}(\mathrm{ox})_{3}$. $10 \mathrm{H}_{2} \mathrm{O}(\mathrm{M}=\mathrm{Cr}, \mathrm{Co}, \mathrm{Ru}, \mathrm{La})$. Inorg. Chem. 2015, 54, 8529-8535. (h) Guo, F.; Chen, C.; Wang, K.; Zhang, Q.; Lin, Z. Supramolecular Templating Approach for the Solvent-free Synthesis of OpenFramework Metal Oxalates. Inorg. Chem. 2016, 55, 7817-7819.

(11) (a) Kitagawa, S.; Kawata, S. Coordination compounds of 1,4 dihydroxybenzoquinone and its homologues. Structures and properties. Coord. Chem. Rev. 2002, 224, 11-34. (b) Abrahams, B. F.; Hudson, T. A.; McCormick, L. J.; Robson, R. Coordination Polymers of 2,5-Dihydroxybenzoquinone and Chloranilic Acid with the (10,3)-a Topology. Cryst. Growth Des. 2011, 11, 2717-2720. (c) Mercuri, M. L.; Congiu, F.; Concas, G.; Sahadevan, S. A. Recent Advances on Anilato-Based Molecular Materials with Magnetic and/or Conducting Properties. Magnetochemistry 2017, 3, 17.

(12) Atzori, M.; Benmansour, S.; Mínguez Espallargas, G.; ClementeLeón, M.; Abhervé, A.; Gómez-Claramunt, P.; Coronado, E.; Artizzu, F.; Sessini, E.; Deplano, P.; Serpe, A.; Mercuri, M. L.; Gómez-García, C. J. A Family of Layered Chiral Porous Magnets Exhibiting Tunable Ordering Temperatures. Inorg. Chem. 2013, 52, 10031-10040.

(13) Abhervé, A.; Clemente-León, M.; Coronado, E.; Gómez-García, C. J.; Verneret, M. One-Dimensional and Two-Dimensional AnilateBased Magnets with Inserted Spin-Crossover Complexes. Inorg. Chem. 2014, 53, 12014-12026.

(14) Abhervé, A.; Mañas-Valero, S.; Clemente-León, M.; Coronado, E. Graphene related magnetic materials: micromechanical exfoliation of 2D layered magnets based on bimetallic anilate complexes with inserted $\left[\mathrm{Fe}^{\mathrm{III}}\left(\mathrm{acac}_{2} \text {-trien }\right)\right]^{+}$and $\left[\mathrm{Fe}^{\mathrm{III}}\left(\mathrm{sal}_{2} \text {-trien }\right)\right]^{+}$molecules. Chem. Sci. 2015, 6, 4665-4673.

(15) Darago, L. E.; Aubrey, M. L.; Yu, C. J.; Gonzalez, M. I.; Long, J. R. Electronic Conductivity, Ferrimagnetic Ordering, and Reductive Insertion Mediated by Organic Mixed-Valence in a Ferric Semiquinoid 
Metal-Organic Framework. J. Am. Chem. Soc. 2015, 137, 1570315711.

(16) Jeon, I. R.; Negru, B.; Van Duyne, R. P.; Harris, T. D. A 2D Semiquinone Radical-Containing Microporous Magnet with SolventInduced Switching from $T_{\mathrm{c}}=26$ to $80 \mathrm{~K}$. J. Am. Chem. Soc. 2015, 137, 15699-15702.

(17) DeGayner, J. A.; Jeon, I. R.; Sun, L.; Dinca, M.; Harris, T. D. 2D Conductive Iron-Quinoid Magnets Ordering up to $T_{\mathrm{c}}=105 \mathrm{~K}$ via Heterogenous Redox Chemistry. J. Am. Chem. Soc. 2017, 139, 41754184.

(18) Benmansour, S.; Abhervé, A.; Gómez- Claramunt, P.; Vallés -García, C.; Gómez García, C. J. Nanosheets of Two-Dimensional Magnetic and Conducting $\mathrm{Fe}(\mathrm{II}) / \mathrm{Fe}(\mathrm{III})$ Mixed-Valence MetalOrganic Frameworks. ACS Appl. Mater. Interfaces 2017, 9, 2621026218.

(19) Atzori, M.; Artizzu, F.; Sessini, E.; Marchiò, L.; Loche, D.; Serpe, A.; Deplano, P.; Concas, G.; Pop, F.; Avarvari, N.; Mercuri, M. L. Halogen-bonding in a new family of tris(haloanilato)metallate(III) magnetic molecular building blocks. Dalton Trans. 2014, 43, 70067019.

(20) Altomare, A.; Burla, M. C.; Camalli, M.; Cascarano, G. L.; Giacovazzo, C.; Guagliardi, A.; Moliterni, A. G. G.; Polidori, G.; Spagna, R. SIR97: a new tool for crystal structure determination and refinement. J. Appl. Crystallogr. 1999, 32, 115-119.

(21) Sheldrick, G. M. A short history of SHELX. Acta Crystallogr., Sect. A: Found. Crystallogr. 2008, A64, 112-122.

(22) Farrugia, L. J. WinGX and ORTEP for Windows: an update. J. Appl. Crystallogr. 2012, 45, 849-854.

(23) WinDETA; Novocontrol GmbH: Hundsangen, Germany, 1995.

(24) Halis, S.; Inge, A. K.; Dehning, N.; Weyrich, T.; Reinsch, H.;

Stock, N. Dihydroxybenzoquinone as Linker for the Synthesis of Permanently Porous Aluminum Metal-Organic Frameworks. Inorg. Chem. 2016, 55, 7425-7431.

(25) Luo, T.; Liu, Y.; Tsai, H.; Su, C.; Ueng, C.; Lu, K. A Novel Hybrid Supramolecular Network Assembled from Perfect $\pi-\pi$ Stacking of an Anionic Inorganic Layer and a Cationic Hydronium-IonMediated Organic Layer. Eur. J. Inorg. Chem. 2004, 2004, 4253-4258.

(26) Kingsbury, C. J.; Abrahams, B. F.; D’Alessandro, D. M.; Hudson, T. A.; Murase, R; Robson, R.; White, K. F. Mixed Valency in a 3D Semiconducting Iron-Fluoranilate Coordination Polymer. Cryst. Growth Des. 2017, 17, 1465-1470.

(27) Mínguez Espallargas, G.; Brammer, L.; Allan, D. R.; Pulham, C. R; Robertson, N.; Warren, J. E. Noncovalent Interactions under Extreme Conditions: High-Pressure and Low-Temperature Diffraction Studies of the Isostructural Metal-Organic Networks (4-Chloropyridinium $)_{2}\left[\mathrm{CoX}_{4}\right](\mathrm{X}=\mathrm{Cl}, \mathrm{Br})$. J. Am. Chem. Soc. 2008, 130, 90589071.

(28) Colomban, P. Proton Conductors: Solids, Membranes and Gels Materials and Devices. Chemistry of Solid State Materials; Cambridge University Press: Cambridge, U.K., 1992; Vol. 2.

(29) Grancha, T.; Ferrando-Soria, J.; Cano, J.; Amorós, P.; Seoane, B.; Gascon, J.; Bazaga-García, M.; Losilla, E. R.; Cabeza, A.; Armentano, D.; Pardo, E. Insights into the Dynamics of Grotthuss Mechanism in a Proton- Conducting Chiral bioMOF. Chem. Mater. 2016, 28, 4608-4615.

(30) Yamada, T.; Morikawa, S.; Kitagawa, H. Structures and Proton Conductivity of One-Dimensional $\mathrm{M}(\mathrm{dhbq}) \cdot \mathrm{nH} 2 \mathrm{O}(\mathrm{M}=\mathrm{Mg}, \mathrm{Mn}$, $\mathrm{Co}, \mathrm{Ni}$, and $\mathrm{Zn}, \mathrm{H} 2(\mathrm{dhbq})=2,5$-Dihydroxy-1,4-benzoquinone) Promoted by Connected Hydrogen-Bond Networks with Absorbed Water. Bull. Chem. Soc. Jpn. 2010, 83, 42-48. 